\title{
Exploring a Prefigurative Culture in the Immigrant Family: A look at the sociolinguistic impact of children on the immigrant parent
}

\author{
Melissa Katherine Mclntosh \\ West Virginia University
}

Follow this and additional works at: https://researchrepository.wvu.edu/etd

\section{Recommended Citation}

McIntosh, Melissa Katherine, "Exploring a Prefigurative Culture in the Immigrant Family: A look at the sociolinguistic impact of children on the immigrant parent" (2013). Graduate Theses, Dissertations, and Problem Reports. 424.

https://researchrepository.wvu.edu/etd/424

This Dissertation is protected by copyright and/or related rights. It has been brought to you by the The Research Repository @ WVU with permission from the rights-holder(s). You are free to use this Dissertation in any way that is permitted by the copyright and related rights legislation that applies to your use. For other uses you must obtain permission from the rights-holder(s) directly, unless additional rights are indicated by a Creative Commons license in the record and/ or on the work itself. This Dissertation has been accepted for inclusion in WVU Graduate Theses, Dissertations, and Problem Reports collection by an authorized administrator of The Research Repository @ WVU.

For more information, please contact researchrepository@mail.wvu.edu. 
Exploring a Prefigurative Culture in the Immigrant Family: A look at the sociolinguistic impact of children on the immigrant parent

\author{
Melissa Katherine McIntosh \\ Dissertation submitted \\ to the College of Education and Human Services \\ at West Virginia University \\ in partial fulfillment of the requirements for the degree of \\ Doctor of Education \\ in \\ Curriculum and Instruction \\ Patricia Obenauf, Ed.D, Chair \\ David Callejo, Ed.D. \\ Joy Faini Saab, Ed.D. \\ Perry Phillips, Ed.D. \\ Ahmed Fakhri, Ph.D. \\ Department of Curriculum and Instruction
}

Morgantown, West Virginia

2013

Keywords: Motivation, Acculturation, ESL, Immigration, Hispanics, Latinos Copyright 2013 Melissa Katherine McIntosh 


\begin{abstract}
Exploring a Prefigurative Culture in the Immigrant Family: A look at the sociolinguistic impact of children on the immigrant parent
\end{abstract}

\author{
Melissa Katherine McIntosh
}

According to the U.S. Census Bureau (2010), 12.9\% of the population in the United States is that of immigrants. With this increase in recent immigration, the population of limited English speakers has also increased which includes both children and adults. While much research has been done in terms of how bilingualism and biculturalism have impacted the children within immigrant families, very few studies have focused on the parents and how the children's English language learning and acculturation have impacted their own English learning and acculturation. This study was intended to fill that lack of research by exploring the sociolinguistic impact that children are having on their immigrant parents. This research had three main goals: 1.) to determine the effect of children on the parent's acculturation level, 2.) to determine the effect of children on the parent's motivation to learn English, and 3) to explore the effect of the English language use on the family structure of these immigrant families. This study used a survey questionnaire to measure the impact of children on their Hispanic immigrant parents in terms of acculturation and motivation/attitude toward the English language. Four hundred surveys were distributed at multicultural events focused on the Hispanic population in Denver, Colorado. Both quantitative and qualitative analysis were used to analyze the data. The statistical analysis showed that these participants had an overall low acculturation level, but a high motivation and attitude toward the English language regardless of the children-related demographic factors. However, through the qualitative analysis it was found that the children's English language use was in fact impacting the immigrant parent's motivation to learn the English language as well as altering the roles and practices within the family. 
Exploring a Prefigurative Culture in the Immigrant Family: A look at the sociolinguistic impact of children on the immigrant parent

Melissa Katherine McIntosh

Dissertation submitted

to the College of Education and Human Services

at West Virginia University

in partial fulfillment of the requirements for the degree of

Doctor of Education

in

Curriculum and Instruction

\section{APPROVAL OF THE EXAMINING COMMITTEE}
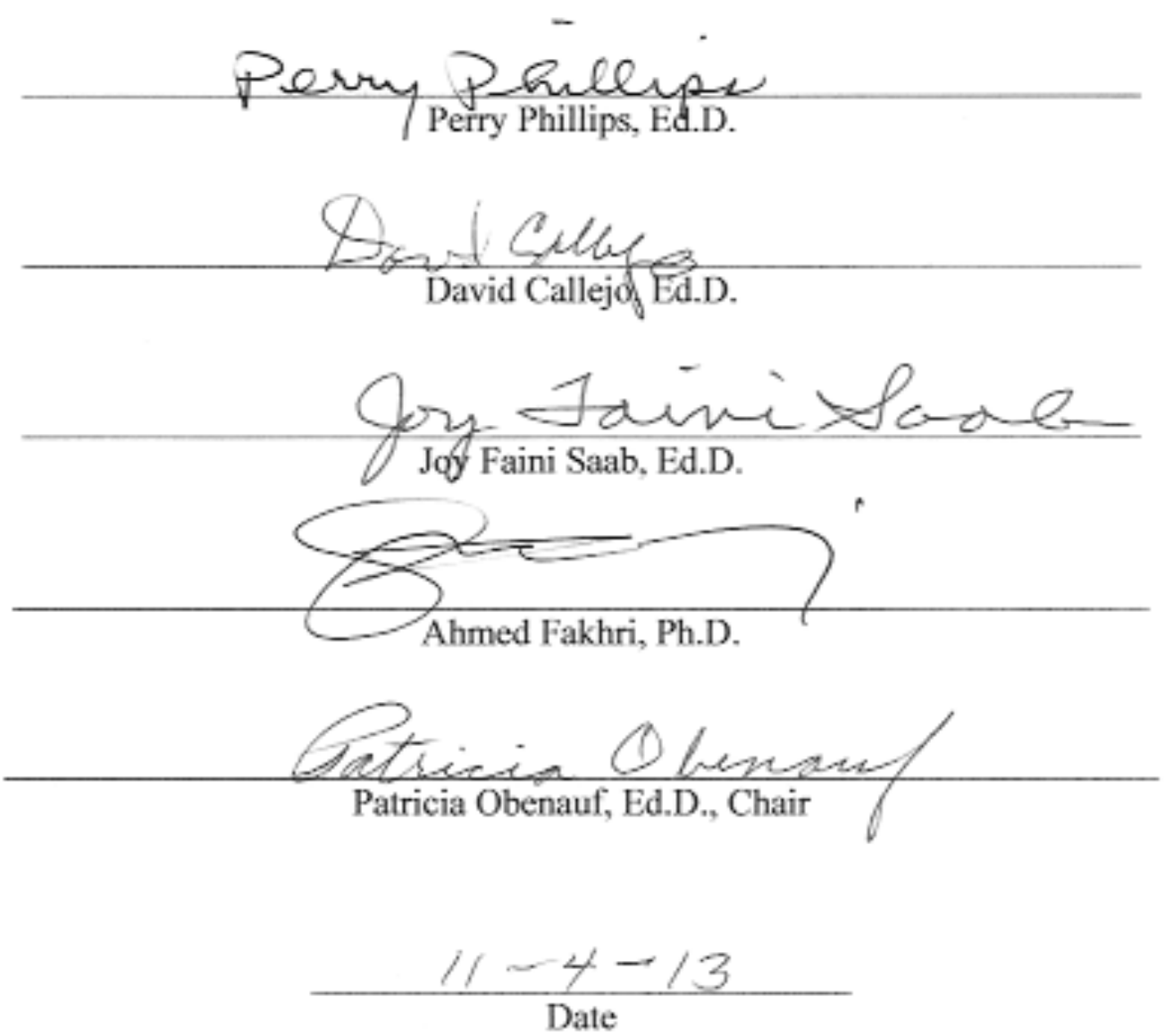


\section{Dedication}

For my husband, Raji, and our two beautiful girls, Yasmeen and Lina 


\section{Acknowledgments}

All thanks to ALLAH for giving me the strength, patience, and motivation to complete my study. Without the dedication to my faith, none of this would be possible.

Secondly, I would like to thank my family, both in the United States and Saudi Arabia, for supporting me and believing in my goal to finish this project. Without your love and encouragement, this would have been an impossible journey.

I would also like to thank the Multicultural Outreach Office for the Denver Public Schools for their interest in my research and for distributing my surveys at their multicultural events.

Finally, I would like to thank my doctoral committee, Dr. Patricia Obenauf, Dr. David Callejo, Dr. Perry Phillips, Dr. Joy Faini Saab, and Dr. Ahmed Fakhri. Thank you for your patience and expertise in my research. Each of you has guided me and encouraged me throughout my study. Thank you again for your work with me. 


\section{Table of Contents}

\section{Chapter 1: Introduction}

Background of Study

Purposes

Research Questions

Hypotheses

Significance of the Study

Limitations of the Study

Organization of the Study

Definitions

2: Literature Review

Introduction

Section One: The Hispanic Acculturation Experience

Familism

Language Brokering

Conclusion

Section Two: Motivation and Attitude in Second Language Acquisition Introduction

Motivation: Integrative and Instrumental

Self-Determination Theory

The L2 Motivational Self System

Conclusion

Chapter 3: Methodology

Introduction

Population/Sample

Procedure/Instrumentation

Translation of the Survey and Questionnaire IRB Approval

Pilot Study

Analysis

Chapter 4: Results and Analysis

Introduction

61

Acculturation Level of Immigrant Parents

Motivation Toward Learning English

Statistical Analysis

Qualitative Analysis

Conclusion

\section{Chapter 5: Discussion and Conclusion}

Summary

Discussion of Findings

Recommendations for Greater Community Outreach 


\section{Chapter 1: Introduction}

\section{Background of the Study}

For many cultures, it is natural that the elder generation teaches and influences the younger generation; however, what happens when these cultures are placed within a larger, more diverse society in which the adults have yet to acquire the specific cultural aspects of the new society? Over forty years ago, Margaret Mead stated that the postfigurative culture "in which children learn primarily from their forebears" would eventually evolve into a prefigurative culture " in which adults learn also from their children" (Mead, 1970, p.1). While this claim was intended to characterize society and culture as a whole, specific cultures and situations that arise within these cultures may cause a prefigurative culture to exist over a postfigurative culture. "I call this new style prefigurative, because in this new culture it will be the child-and not the parent and grandparent that represents what is to come" (Mead, 1970, p.88). More than forty years have passed since this initial statement of cultural evolution and very few studies have taken this claim into account. Prefigurative culture has not been explored in immigrant communities, particularly within immigrant families in a pluralist society, where they must address acculturation and language. This study explored the existence of a prefigurative culture within immigrant communities in the United States in terms of English language education by looking at the impact of children on adult English language learners.

Over the past forty years, the United States has seen a shift in immigration from purely European to consisting of people from various parts of the world for various reasons stemming from such issues as war, political shifts, natural disasters, financial 
situations, etc. Massey (1995) states, "the remarkable amalgamation of European immigrants into the society and culture of the United States is a historical fact" (p. 640). Whereas the European immigrants of the early twentieth century seem to have assimilated easily to the new culture, recent immigrants of the twenty-first century may not have encountered the need to fully assimilate into the American culture. This may be due to the many separate unique cultural communities throughout most of the United States, which has limited the access to the outside culture. "National origins and geographic destinations of the new immigrants are highly concentrated, creating large foreign-language and cultural communities in many areas of the United States" (Massey, 1995, p. 648). Some examples of these cultural communities in the United States include the Cubans in Miami, the Arabs in Dearborn, Michigan, and the Chinese in San Francisco. While these pockets of immigrant communities do exist, it does not eliminate the fact that they make up part of the United States and thus part of the larger society. According to the U.S. Census Bureau (2010), 12.9\% of the population in the United States is that of immigrants. With this influx of immigrants now making their home in the United States, there is an increase in awareness to their needs in the new society.

One of these needs, which must be addressed, is the English language. With this increase in recent immigration, the population of limited English speakers has also increased which includes both children and adults. While many of the school districts have at least taken the initiative to respond to this need of the limited English students, the adults have been overlooked in these communities. The children in these immigrant communities are being educated bilingually, whether they receive their first language at school or only at home. "Although many children in immigrant families are limited 
English proficient (26\%), nearly twice as many (46\%) speak a language other than English at home, but also speak English very well. These children are well positioned to become fluent bilingual speakers" (Lansford, Deater-Deckard, \& Bornstein, 2007, p.18). This notion of bilingual children is interesting and brings up many important questions to address in terms of community and family. These children are leaving their immigrant parents, most of who live in ethnic communities where the English language is not vital for survival, to attend American schools everyday. They are being assimilated into the American school system with American English-speaking students and teachers, while their parents spend most of the time around people of their same background. While the children are adapting to the larger society, the parents must find a way to understand their child's new culture. Research has already been done on the way bilingualism and bilingual education affect children; however, other questions remain as to how bilingual children are affecting the adult population in their own English language learning in terms of sociolinguistic aspects, including acculturation, motivation, and attitude.

\section{Purposes}

The purpose of this study was to determine if a prefigurative culture exists in immigrant families in the United States. It intended to determine if the education of bilingual children is affecting the adult population; and if the child's experience with learning English is influencing the adults' acquisition of English. This was explored by analyzing the immigrant parent's experience of their English language learning in relation to their child's bilingualism. The areas of acculturation, motivation, and attitude in second language acquisition of adult immigrants was explored using a survey as well as qualitative questioning and was focused on the Hispanic/Latino immigrant 
community due to this group's recent and ongoing immigration. The terms, "Hispanic" and "Latino" are used interchangeably in most studies. Hispanic and Latino refer to a group of people with their origin in Puerto Rico, Cuba, Dominican Republic, Mexico, Central America, and South America. The studies that were looked at in this research used the two terms interchangeably and were focused on Spanish-speaking people. The researcher will use the term Hispanic to identify the group being looked at in this study. "Latinos are now the largest U.S. minority population (12.5\% vs. $12.3 \%$ for African American); 35.3 million Latinos live in the United States (an increase of 58\% since 1990); and Latinos are $52 \%$ of the foreign-born population in the United States (from $31 \%$ in 1980 to $42 \%$ in 1990)" (Lansford, Deater-Deckard, \& Bornstein, 2007, p.1). According to the U.S. Census Bureau (2010), 53.1\% of the foreign born population in the United States come from Latin America and the Carribbean (see Table 1). Hispanics are the largest immigrant community in the United States today and their population growth only increases the need to understand their situation in the larger community in order to improve their chances of flourishing in the American society through improved ESL community programs. 
Table 1. Foreign-born Population in the United States

\begin{tabular}{|c|c|}
\hline Region of Birth & Percentage \\
\hline Africa & $4.0 \%$ \\
Asia & $28.2 \%$ \\
Europe & $12.1 \%$ \\
Latin America and Caribbean & $53.1 \%$ \\
Northern America & $2.0 \%$ \\
Oceania & $0.5 \%$ \\
\hline
\end{tabular}

U.S. Census Bureau (2010)

\section{Research Questions}

This study was guided by four main research questions. These questions were explored through both quantitative and qualitative methods. The following are the research questions that were addressed in this study:

(1) How are children impacting the acculturation of the immigrant parent in the United States?

$\mathrm{Q}_{1}$ : Does the number of children have an effect on the immigrant parent's acculturation level?

$\mathrm{Q}_{2}$ : Does the age of children have an effect on the immigrant parent's acculturation level?

$\mathrm{Q}_{3}$ : Does the gender of children have an effect on the immigrant parent's acculturation level?

Q4: Does the English language level of children have an effect on the immigrant parent's acculturation level?

(2) How are children impacting the immigrant parent's motivation to learn the English language in the United States? 
$\mathrm{Q}_{1}$ : Does the number of children have an effect on the immigrant parent's motivation to learn English?

$\mathrm{Q}_{2}$ : Does the age of children have an effect on the immigrant parent's motivation to learn English?

$\mathrm{Q}_{3}$ : Does the gender of children have an effect on the immigrant parent's motivation to learn English?

$\mathrm{Q}_{4}$ : Does the English language level of children have an effect on the immigrant parent's motivation to learn English?

(3) What are the main motivating factors of the immigrant parent for learning the English language?

(4) How have the children's English language learning affected the family unit in the United States?

$\mathrm{Q}_{1}$ : How have the roles within the family been affected by the English language?

$\mathrm{Q}_{2}$ : How have the children's English language learning impacted the practice of the native language and culture within the family?

Hypotheses

This study used eleven hypotheses to address the research questions. $\mathrm{H}_{1-8}$ will be null hypothesis to correspond with the quantitative questions while $\mathrm{H}_{9-11}$ will be based on the literature review. The following are the hypotheses used:

$\mathrm{H}_{1}$ : There is no significant effect of the number of children on the immigrant parent's acculturation level.

$\mathrm{H}_{2}$ : There is no significant effect of the age of children on the immigrant parent's acculturation level.

$\mathrm{H}_{3}$ : There is no significant effect of the gender of children on the immigrant parent's acculturation level. 
$\mathrm{H}_{4}$ : There is no significant effect of the English language level of children on the immigrant parent's acculturation level.

$\mathrm{H}_{5}$ : There is no significant effect of the number of children on the immigrant parent's motivation to learn the English language.

$\mathrm{H}_{6}$ : There is no significant effect of the age of children on the immigrant parent's motivation to learn the English language.

$\mathrm{H}_{7}$ : There is no significant effect of the gender of children on the immigrant parent's motivation to learn the English language.

$\mathrm{H}_{8}$ : There is no significant effect of the English language level of the children on the immigrant parent's motivation to learn the English language.

$\mathrm{H}_{9}$ : Motivation to learn the English language will include both integrative and instrumental factors.

$\mathrm{H}_{10}$ : Children are now taking a more active and responsible role within the family because of the English language.

$\mathrm{H}_{11}$ : The children's English language learning has reduced the presence and importance of the native language and culture within the family.

Significance of the Study

The need for this study is great due to the newly diverse demographics that are forming in cities and towns throughout the United States. In order to help this new population become contributing members to society, we must understand their experiences while they are in the new culture. This includes both the child's experience and the adult's experience. While many studies have already addressed the experiences of bilingualism and immigrant children, very few studies (Gordon, 1996; Kim \& Miura, 
1999; Worthy, 2006; Souto-Manning, 2007) have looked at immigrant parents in depth and even fewer have addressed their English language learning in the second language culture. This study explored the factors of acculturation, motivation, and attitude of immigrant parents, which will allow community ESL program coordinators to better understand these adult students and accommodate their needs, which will eventually benefit their children who will become the future of the larger society. Ultimately the study aims to provide insight into ways that undeveloped language centers in prime immigrant communities can improve on community outreach.

\section{Limitations of the Study}

The following are some possible limitations that the study may have:

(1). No previous studies have looked at second language acquisition in relation to a prefigurative culture; therefore, there are not specific research guidelines or results to compare this study to.

(2). No previous studies have looked at the social implications of being a parent in learning English as a Second Language.

(3). This study does not take into account all demographic factors of the adult population.

(4). This study is limited to a small sample of one specific cultural group (Hispanics) and does not take into account other cultural groups.

\section{Organization of the Study}

This study is organized into five chapters. Chapter one is divided into seven parts: background of the study, purposes, research questions, significance of the study, limitations of the study, organization of the study, and definitions. Chapter two consists 
of the literature review, which looks at the Hispanic acculturation experience and the affective factors of motivation and attitude in second language acquisition. Chapter three discusses the methodology used in this study. Chapter four includes the results and an analysis. Chapter five is composed of the conclusion and discussion of the results and analysis.

\section{Definitions}

1. Prefigurative Culture: A prefigurative culture is a culture in which the younger generation influences and becomes the teachers and leaders of the older generation.

2. English as a Second Language (ESL): ESL refers to the English language being learned or taught in an English-speaking country as a second language.

3. Second Language Acquisition (SLA): SLA refers to the process of learning and becoming proficient in a second language or a language other than your native language. 4. Sociolinguistic: Sociolinguistic refers to social variables having an impact on language.

5. Acculturation: Acculturation is the cultural and psychological changes that occur when two different cultures come into contact. Berry (1997) states that there are four strategies to acculturation: assimilation, separation, integration, and marginalization.

6. Language Brokering: Language brokering is the process of someone acting as a translator or interpreter of a language for another.

7. Cultural Brokering: Cultural brokering is the process of one person explaining cultural aspects of a community and way of life to another who is unfamiliar with the cultural customs of a community. 
8. Motivation: In terms of motivation in language learning, it refers to the attitude and desire to learn a language. According to Gardner and Lambert (1959), motivation in second language learning has two orientations: instrumental and integrative.

9. Affective Factors: Affective factors are personal factors that affect second language acquisition. These factors include motivation, anxiety, and personality.

10. 2LL: $2 \mathrm{LL}$ refers to the second language learner, or the person learning another language.

11.Target Language: The target language refers to the language that one aims to acquire. In the case of this study and ESL, the target language is English.

12. Target Culture: The target culture refers to the main culture of a society. In this study, the target culture is the American culture.

13. L2: L2 refers to the second language. In this study, the L2 is English.

14. Latino: The term Latino is used interchangeably with the term Hispanic. It refers to people with an origin in Puerto Rico, Cuba, Dominican Republic, Mexico, Central America, and South America.

15. Hispanic: The term Hispanic is used interchangeably with the term Latino. It refers to people with an origin in Puerto Rico, Cuba, Dominican Republic, Mexico, Central America, and South America. The researcher will use the term Hispanic to identify the group of people being looked at in this study. 


\section{Chapter 2: Literature Review \\ Introduction}

The literature review provides a background into the issues that were addressed in this study. It is divided into two sections. Section one addressed the contextual background of the study, which focused on the Hispanic acculturation experience in the United States. In particular, this section focused on familism and language broking within the Hispanic community in the United States. Section two addressed the theoretical framework of the study, which reviewed the studies of motivation and attitude in Second Language Acquisition. Issues such as the relationship between acculturation and motivation, integrative and instrumental motivation, self- determination theory, and the L2 Motivational Self System were examined.

Section One: The Hispanic Acculturation Experience in the United States According to Trimble (2003):

Acculturation has been used to better understand the modernization processes that various cultures and communities were undergoing during the 19th and early 20th centuries. More recently, acculturation became an important concept in the explanation of the varied experiences of ethnic and cultural minorities as international migration, economic globalization, and political conflicts supported the creation of multicultural societies. (p.5)

As suggested by Trimble (2003), the experiences of cultural groups have become much more diverse and acculturation cannot be looked at from solely an "immigrant" context. It must, however, be analyzed on an individual basis that takes into account culture, language, ethnicity, social situation, and the individual circumstances that brought them 
to where they are today. However, before one can break down the acculturation experience of an individual, an understanding of the basic concepts of acculturation must be established.

It is important to understand that acculturation is a process through which one must participate. Through this process one may become high acculturated or low acculturated depending on the interactions that occur during this process. Teske and Nelson (1974) explain this more thoroughly in their discussion on the process of acculturation. They emphasize the importance that dominance plays in the acculturation process. "When a dominate-subdominate relationship exists between two cultural groups, this relationship does affect the direction and degree of acculturation" (Teske \& Nelson, 1974, p. 356). In relation to the concept of dominance in acculturation, they explain in terms of complete dominance or parity. Within complete dominance, one culture maintains a higher status than the other culture; whereas, in parity, both cultures exclude one another. Complete dominance would establish the direction of acculturation as unidirectional, meaning that acculturation only occurs as a one-way process in that the minority would have to adapt to the cultural values and beliefs of the dominant culture. According to Teske and Nelson (1974), the question of how the degree of acculturation is developed still remains; however, they believe that acculturation is a two-way process that does not require a change in cultural values. Ryder, Alden, and Paulhus (2000) would agree with Teske and Neslon (1974) in this previous claim. They believe that one can maintain two co-existing cultural identities.

Berry (1997) continues the discussion on the issue of dominance and nondominance in the acculturation process. According to Berry (1997), there are four 
acculturation strategies: assimilation, separation, integration, and marginalization; however, they are dependent upon whether the dominant or non-dominant group is being considered. Assimilation occurs when one does not want to retain their cultural identity; however, separation occurs when one wants to maintain their original culture and avoid the target culture. Integration occurs when one wants to maintain their culture, but also interact with the target culture; and marginalization occurs when there is little possibility in keeping their culture, but they do not want to interact with the target culture. These four strategies support the notion that acculturation is at times a complex and diverse process that is highly dependent upon the individual. Berry (1997) continues with his discussion on the acculturation process and his support of the notion that this process varies depending on the person by explaining that the acculturation process is often influenced by variables such as gender, social relationships, and cultural distance which shows the need to look at the social and real life aspects of acculturation.

Acculturation is a term most often heard in pluralistic societies in which immigration is prevalent in daily life. It is a common concept throughout many cities in the United States, Canada, Europe, and Australia where large concentrations of immigrants establish their new homes and way of life. In many of these pluralistic societies, it is typical for cultural specific communities to form, which resemble tiny enclaves within the larger community. While these communities create a safe-haven for the immigrants, it often creates a large gap between them and the outside community that leaves the question of how acculturated can they become or how much desire they have in becoming acculturated in their new society. 
The acculturation of immigrants does not take place in a social vacuum; it occurs and unfolds itself within the context of intragroup and intergroup relations that provide at times the support and at times the challenge for the reconstruction of selves and identities. (Berry, 1997, p.34)

Having little access to the outside community can have implications in terms of familial relationships, independence, and language development. Because of this it is important to study the acculturation levels of new immigrants in society in order to assess their needs to become active participants in the larger community. Since the acculturation process has maintained that it is highly dependent upon social and circumstantial situations, this review of literature is going to focus on a specific group that may share similar social situations and circumstances. The remainder of this literature review will address the Hispanic experience in terms of acculturation. This was chosen because of the relevancy of issues concerning this group in the United States today. In particular, the literature will focus on the family unit within the Hispanic culture in order to give a more focused or thorough look at the acculturation issues facing this group in the United States.

\section{Familism}

Familism is an underlying theme found in much of the literature that is focused on the acculturation process of Hispanics in the United States (Keefe 1979; Vega et al., 1986; Sabogal, Marin, Otero-Sabogal, Marin, \& Perez-Stable, 1987; Rueschenber \& Buriel, 1989; Cuellar, Arnold, \& Gonzalez, 1995; Silverstein \& Chen, 1999; Tseng \& Fuligni, 2000; Duran, 2003; Santisteban \& Mitrani, 2003; Quinones-Mayo \& Dempsey, 2005; Bacallao \& Smokowski, 2007; Cortez, 2008; Schofield, Parke, Kim, \& Coltrane, 
2008; Smokowski, Rose, \& Bacallao 2008). "Familism involves a deeply ingrained sense of the individual being inextricably rooted in the family" (Bacallao \& Smokowski, 2007, p.53). This cultural value instills the sense of close connections, responsibility, and reliability within the family. This characteristic shows that family is the most important factor and all members have an obligation to one another. Familism is a concept that is deeply rooted in the Latino/Hispanic dynamic (Sabogal et al. 1987; Cuellar et al., 1995; Bacallao \& Smokowski, 2007; Smokowski et al., 2008).

The value of familism becomes questionable in the discussion on acculturation. According to Santisteban \& Mitrani (2003):

Acculturation also plays a role in the power structure of the family. The family member with greater cultural competence in White American culture is better prepared to negotiate with powerful extrafamilial systems such as schools, courts, and social service agencies. An employed person may be more exposed to the values of the host society and therefore may acculturate faster and to a greater degree. (p.126)

The following literature investigates the impact that these acculturation divisions have on the family structure in a Hispanic context. These acculturation divisions are explored through issues of cohesion, acculturation gaps, and role reversal in the family unit.

Many studies have shown that as acculturation increases, family cohesion begins to break down (Sabogal et al., 1987; Tseng \& Fuligni, 2000; Smokowski et al., 2008). The reasoning behind this may be due to several factors. As one becomes more acculturated, depending on the acculturation strategy as explained by Berry (1997), they begin to identify more with the target culture and lose sight of their native cultural values. 
The Smokowski et al. (2008) study looked at how adolescent and parent acculturation affected the family dynamics in North Carolina and Arizona. The first thing to consider would be that these two areas have large Hispanic population which may cause some of the results from their study to be less prominent than in a geographic location with fewer Hispanics. They found that "acculturation conflict, the strongest risk factor, was inversely associated with family cohesion, adaptability, familism, and parent-adolescent conflicts" (p. 307). However, "the majority of evidence showed that U.S. cultural involvement was a cultural asset related to higher family cohesion, adaptability, and familism, and lower parent-adolescent conflict" (Smokowski et al., 2008, p.304). This shows that lower cohesion occurs when there is a difference in acculturation levels amongst different members of the family; however, when the family experiences acculturation together, the characteristics of familism stay intact.

The Tseng \& Fuligni (2000) study showed that the loss of cultural characteristics does play a role in lower cohesion within the family. This study investigated the relationships between immigrant parents and children in relation to the language they speak with one another. They found that:

Adolescents who conversed with their parents in different languages felt more emotionally distant from them and were less likely to engage in discussions with them than were youths who shared the same language with their parents. In addition, parents and adolescents who mutually communicated in the native language reported highest cohesion and discussion. (p.473) 
This loss of language may be due to acculturation of the adolescent which emphasizes the division of acculturation within the family and how it may negatively impact the dynamics and relationships.

While some studies have supported the notion that higher acculturation leads to a lower level of cohesion, others have found that acculturation has no effect on the level of cohesion (Keefe, 1979; Vega et al., 1986; Rueschenberg \& Buriel 1989). Keefe's (1979) study compares the extended family composition of Mexican Americans to Anglo Americans when they urbanize and acculturate. She found that overall the Mexican American family is more cohesive than the Anglo American family regardless of urbanization. With the factor of urbanization and acculturation, she found that "the local extended family is retained in urban life by Mexican Americans. Moreover, the extended family becomes stronger with generational advancement, acculturation, and socioeconomic mobility" (p.360).

Rueschenberg \& Buriel (1989) showed that through family acculturation, the cohesiveness within the family does not change. The integration within the United States culture does not affect their original cultural values. They concluded that "patterns of intrafamilial relationships and interactions do not appear to differ substantially from one generation to the next despite the fact that English becomes the primary language and family members become active participants in U.S. society" (p.241). This study does not take into account the fact that family members may acculturate at different levels and time frames which may affect the level of family cohesiveness.

Within the process of acculturation, gaps in the level of acculturation may develop between the various members of the family which affects the family structure 
and the perceived importance of familism (Silverstein \& Chen, 1999; Santisteban \& Mitrani, 2003; Bacallao \& Smokowski, 2007; Cortez, 2008; Schofield et al., 2008). Such issues that arise in the discussion on acculturation gaps include the struggle to retain cultural values, beliefs, and relationships within the family (Silverstein \& Chen, 1999; Santisteban \& Mitrani, 2003; Cortez, 2008), and conflict and stress within the family unit (Bacallao \& Smokowski, 2007; Schofield et al., 2008).

According to Cortez (2008):

For many immigrant families in the United States it is particularly challenging to continue practicing their values and beliefs since they are often not valued.

Furthermore, families are expected to fully integrate in schools, which frequently means leaving their home culture and language behind. (p.97)

This illustrates the struggle that families often face in hopes of placing their values in the central focus of the family. This becomes an issue particularly between the parents who want to maintain the beliefs and relationships they are accustomed to and the children who are acculturating at a rapid pace due to schooling and the forming of new relationships outside of the family and cultural unit.

Silverstein \& Chen (1999) investigated the change that occurs across generations in Mexican American families. In particular, their study addressed the relationship between grandparents and grandchildren. This study was interesting in that the perspective of relationship and interaction differed among family members. Grandchildren who were highly acculturated felt distant from their grandparents; however, the grandparents did not see this distance. Some may argue that this feeling of distance is broadened through the issue of language loss and the acquisition of a new 
language (Tseng \& Fuligni, 2000; Cortez, 2008); however, Silverstein \& Chen (1999) did not find this to be the case. The subjects in their study reported distance between their grandparents when language ability was controlled.

This implies that communication difficulties due to language barriers are only part of the reason for lower rates of affiliation between the generations (as reported by the grandchildren) and lends support to the view that adult Mexican American grandchildren who live in different cultural worlds than their grandparents are less inclined to interact with them. (Silverstein \& Chen, 1999, p.196)

This suggests that as one becomes more acculturated, the importance of familism may decrease and the gap that occurs between the different generations allows for perspectives in terms of family relationships and cultural values to differ.

In addition to Silverstein \& Chen (1999), Santisteban \& Mitrani (2003) do not blame the acculturation gap on language alone. They see that the experiences of the more acculturated children are not relatable to the experiences of the culturally sheltered parents. "Even when there is a shared language, however, there may be little overlap between the shared experiences and interest of parents and adolescents because of acculturation differences, meaning that they have fewer opportunities to share intimate family moments and other bonding opportunities" (Santisteban \& Mitrani, 2003, p. 129). These acculturation differences may cause frustrations and misunderstandings which may break down the cohesiveness within the family unit.

Stress and conflict is a common consequence that comes about from differences within family member's acculturation level, especially between parent and child (Bacallao \& Smokowski, 2007; Schofield et al., 2008). According to Bacallao \& 
Smokowski (2007), “acculturation gaps between family members contribute to intergenerational stress, and familism tends to erode over time spent in the United States" (p.53). This was not only due to widening gaps between acculturation levels, but also other issues that would arise in the new culture such as more time spent apart due to school and work demands. Schofield et al. (2008) also saw that these conflicts were not only based on acculturation gaps alone, but as well as other variables that influenced these conflicts and stresses in the new society. They discovered that conflicts and stresses were dependent upon the family member when acculturation gaps were concerned. For example, conflicts were present with father-child acculturation gaps, but not with mother-child acculturation gaps. This may be due to the closeness of the relationship even before immigration and acculturation differences existed. They found that most conflicts were the result of a previously strained relationship suggesting that "acculturation gaps between family members may function as a stressor but can be less disruptive in families that have well-functioning relationships between parents and children" (p.1193). However, over time these acculturation gaps may have negative consequences on the relationship, which in turn, my enforce a breakdown of cohesiveness within the family and place added stress on the situation.

With these acculturation differences, role reversals within the family become common in which the more acculturated member of the family, most often the children, start to take a more responsible role in order for the family to survive in the new culture. This is a strong characteristic of the concept of familism in the Hispanic context. Recognizing that the family unit is important, the children take on this added burden to ensure the well-being of the entire family. The children "help parents and often the 
extended family overcome the gaps created by culture and language differences" (Quinones-Mayo \& Dempsey, 2005, p. 663). With role reversal it is important to analyze how the family dynamic may change in order to truly understand the Hispanic acculturation experience. Duran (2003), Quinones-Mayo and Dempsey (2005), Santisteban and Mitrani (2005), and Bacallao and Smokowski (2007) all take into account role reversal and the implications that this may have for the family unit.

With the concept of role reversal within the family, the parents and guardians start to lose power within the family. The children now take on the adult role, while the parents come to depend on their children. Santisteban \& Mitrani (2003) stress the loss of power that parents experience through role reversal in the family unit.

In most immigrant families, children become fluent in English well before their parents and have less difficulty adapting to the norms of institutional structures. It is not unusal for a child who is the subject of a disciplinary meeting involving parents and school officials to serve as a translator, thus compromising the executive power of parents in the eyes of the school and within the family. (Santisteban \& Mitrani, 2003, p. 128). While Santisteban and Mitrani (2003) saw role reversal as having negative impacts, the parents in the Bacallao and Smokowski (2007) study viewed it in a more positive way. They saw their children's acculturation as necessary and needed in order for the family to meet their day to day needs. "Adolescents' growing knowledge of English placed them in a highly valued position in the family" (Bacallao \& Smokowski, 2007, p. 63). 


\section{Language Brokering}

After discussing the children-parent role reversal, the concept of language and cultural brokering takes on more importance. According to Tse (1995), "language brokers convey messages for people who would otherwise not be able to communicate because of cultural and/or linguistic differences" (p.16). Language brokers are often language minority (LM) children living in the United States with their families. Tse (1995) stated that "nearly all LM children and adolescents act as language brokers, regardless of their length of residence in the US and the availability of older and more knowledgeable brokers in their family" (p.16). In addition to their parents, language brokers often translate for friends, neighbors, siblings, and school officials (Dorner, Orellana, \& Jimenez, 2008). Language brokering can take place anywhere where there is a need for understanding in the new language such as schools, doctors' offices, banks, and the home (Tse, 1995; Dorner et al., 2008).

Several studies have been conducted in the area of language brokering. Within these studies, the main focus has been placed on the experience of the child. The feelings and emotions of the child have been studied (Weisskirch, 2006; Dorner et al., 2008; Martinez, McClure, \& Eddy, 2009; Villanueva \& Buriel, 2010 ) as well as the impact that language brokering may have on academic performance (Tse, 1995; Acoach \& Webb, 2004; Dorner, Orellana, \& Li-Grining, 2007). There have only been a few studies that focus on the experience of the parent (Worthy, 2006; Weisskirch, 2007; Martinez, McClure, \& Eddy, 2009) which shows the need for more research in this area. According to Tse (1996): 
Language brokers, as these interpreters and translators are called, do far more than transmit information. In many cases, they take on the responsibility of making educational and other decisions for themselves and their family, decisions normally made by their parents. Acting as brokers also causes positive and negative affective results that greatly impact students' view of themselves and their language learning experiences. (p.485-6)

Many studies have claimed that children feel proud that they are able to help their families (Weisskirch, 2006) while other children view the brokering process as inconvenient, stressful, problematic, and embarrassing (Dorner et al., 2008; Martinez et al., 2009; Villanueva \& Buriel, 2010).

Weisskirch (2006) looked at the language brokering process from the Mexican American adult child's perspective. In his study, he questioned twenty Mexican American college students about their language brokering experience and found that "adult children of immigrants report that they feel helpful, proud and useful when language brokering. In addition, those who language brokered most frequently had higher self-esteem" (p.340). Weisskirch (2006) was also able to conclude from his study that the level of acculturation also had an impact on their language brokering feelings. For example, those who were more acculturated to the American society felt that they were forced to translate for their families which would also bring out negative feelings about the language brokering process. Since Weisskirch's (2006) study was the only study examined that brought about positive feelings toward the language brokering process, it could be directly related to the fact that these are adult children in which their sense of familism is much greater than a younger child. 
The other studies that focused on the child experience looked at younger children and adolscents which may play a role in the results obtained since they all had negative feelings toward the language brokering process. The Dorner et al. (2008) study looked at how language and cultural brokering impacted the development of immigrant adolescents. They found that adolescents "viewed some translating encounters as inconvenient and others as more problematic" (p. 535). In addition, they found that language brokering was not just an individual experience, but a shared process with many members of the family working together to understand the task. In contrast with Tse's (1995) claim that other brokers in the family did not influence other children's duties in language brokering, Dorner et al. ( 2008) found that in families that had older siblings, the younger children were doing more translating. This implies that the responsibilities that children take on as language brokers may change as the structure and composition of the family changes.

Like Dorner et al. (2008), Martinez et al. (2009) found that language brokering was a family process. Their study looked at the impact that language brokering had on the behavior and emotions of a family, meaning both parent and child. They found that children were under much more stress in a language brokering situation. In addition to stress, emotional health problems, substance abuse, disciplinary problems were also reported. The implications from language brokering in this study suggest some serious issues that must be investigated further. This study also investigated the effects language brokering had on parents. Where there was at least one parent that was bilingual, the impact was much less negative. 
Families in which children were bilingual with two monolingual Spanishspeaking parents reported more paternal depression and stress, and less paternal monitoring, schoolwork monitoring, homework engagement, and positive involvement, as well as less maternal skill encouragement, than families in which children were bilingual but also had at least one bilingual parent. (Martinez et al., 2009, p.90)

Worthy (2006) also viewed the negative emotional impact that language brokering had on the parents involved. The parents involved in this study recognized that if they knew English and did not have to rely on their children, their life would be greatly improved by being able to resume their role as the responsible parent that their child could depend on, and the burden that their children had to take on in an already complicated time in their life would be lessened.

Weisskirch (2007) found a different parental experience in the language brokering process. The results of the parental experience in this study was somewhat divided. It was reported that some parents were happy with the language brokering process because it instilled a sense of responsibility in their children that made them "feel a source of pride in having their children and early adolescents as effective communicators" (Weisskirch, 2007, p. 559). However, many parents still felt that by relying on their child to get by in life lowered their sense of worth as a parent. They felt that they were placing extra responsibility on their children which was often met with frustration and resistance from their children. These studies that focus on the parental experience show that an indepth look has not been taken and there is a need for future research in this area to truly 
understand the process that both children and parents go through emotionally and behaviorally.

Within the child experience of language brokering, some studies have reported on the impacts that are felt in the child's academic performance as a result of language brokering. Tse (1995) and Villanueva \& Buriel (2010) found that language brokering does have some positive effects for children. They all discovered that language brokering aids in the language acquisition of both the first language and the second language. The question as to whether this positive effect on fluency is related to better academic performance remains to be seen. While Tse (1995) and Villanueva \& Buriel (2010) are more cautious to jump to the conclusion that language brokering leads to improved academic performance, the studies of Acoach \& Webb (2004) and Dorner et al. (2007) suggest that the amount of language brokering is linked to better skills in school. Dorner et al. (2007) associated language brokering with increased standardized test scores implying that the more children translated in their homes, the more likely they would perform better on these exams. Acoach \& Webb's (2004) study took a more in depth view of the connection between language brokering and academic performance. They found that language brokering and comfort with the host culture had direct effects on academic performance. Through language brokering, children became more bicultural which increased their self-confidence in school and had a positive link to their GPA. The studies that take academic performance into account are few; therefore, it would be beneficial to see what other areas language brokering may benefit in the area of academia and other important areas of a child's life. 


\section{Conclusion}

The Hispanic acculturation experience through the family unit has shown that family remains a very important factor when adjusting to the changes one goes through in this process. This review of literature has introduced many concepts within familism that must be kept in mind when conducting future studies on the Hispanic family unit. These issues range from maintaining cohesiveness within the family unit to understanding how relationships may change as acculturation levels differ and what this means for the Hispanic family structure. Through the discussion on language brokering in the Hispanic context, one can see that this new process is starting to have lasting effects on the family unit. Therefore, the question remains as to what these effects mean to the individual members of the family and to the Hispanic family unit as a whole. There is a need for future studies to explore how these behaviors within the Hispanic family are going to change, function, and adapt and what this means for immigrants in the United States and the American society. 
Section Two: Motivation and Attitude in Second Language Acquisition Introduction: The relationship between acculturation and motivation

Acculturation has been shown to play a very important role in second language acquisition (SLA) (Gardner \& Lambert, 1959; Schumann, 1978; Krashen, 1982;

Schumann, 1986; Culhane, 2003; Culhane, 2004; Rubenfeld, Sinclair, \& Clement, 2007). Schumann (1978) posits that, "certain social factors can either promote or inhibit contact between the two groups and thus affect the degree to which the 2LL group acculturates which in turn affects the degree to which that group will acquire the target language" ( $\mathrm{p}$. 29-30). Such social factors that affect the acquisition of the second language include social dominance patterns which shows whether the target culture has power over the foreign culture or vice versa; the degree of integration which is characterized by either assimilation, preservation, or adaptation; enclosure which is characterized by the degree of interaction the target group and second language learner group have such as through the sharing of certain community activities; cohesiveness and the size of the second language learner group; congruence and similarities between the target group and second language leaner group; attitudes of both the target group and second language learner group; and the second language learner group's intended length of residence. All of these social factors just described can either have a positive impact or a negative effect on the second language learning process. Schumann continues by saying, "SLA is just one aspect of acculturation and the degree to which a learner acculturates to the TL group will control the degree to which he acquires the second language" (p.34). Whereas Schumann saw the successful acquisition of a second language as a result of the degree of acculturation that one obtains, Rubenfeld, Sinclair, and Clement (2007) view 
acculturation as a result of second language learning. They state that, "acculturation experiences pertaining to both the native culture and the mainstream culture, therefore, represent a relevant psychological outcome of L2 learning" (p.312). This is an issue that should be explored more to gain more understanding of the role that acculturation plays in second language acquisition; that is, whether second language learning encourages acculturation or if acculturation aids in the acquisition of a second language.

Gardner (1985) illustrates a model that shows the impact that acculturation may have on second language acquisition referred to as the socio-educational model. Figure 1 illustrates this model and shows how acculturation and the social environment that Schumann (1978) described impacts several individual differences that affect the success of second language learning. From this model, one can see that the cultural beliefs which are often created as a result of the interaction that a learner may have with the target group will in fact produce a language learning outcome. Therefore, judging by this model, Gardner suggests that acculturation plays a role in the degree of success that one obtains in the acquisition of a second language. 
Figure 1. The socio-educational model. (Gardner 1985)

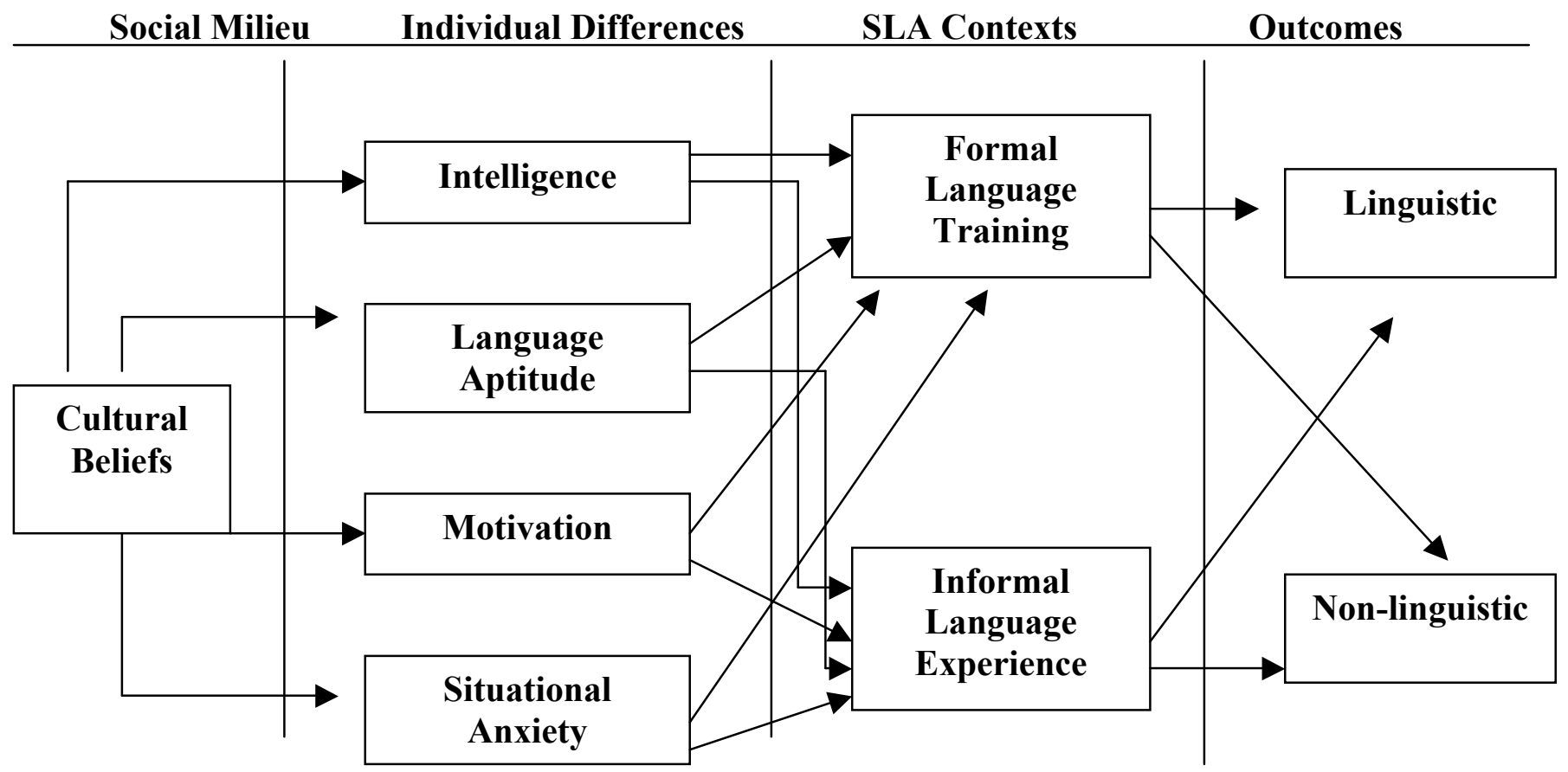

Krashen (1982) has proposed several hypotheses as a researcher that can help explain the acquisition of a second language. The Affective Filter Hypothesis seeks to explain how some personal factors can hinder the language learner depending on the negative aspects of them. "The Affective Filter Hypothesis captures the relationship between affective variables and the process of second language acquisition by positing that acquirers vary with respect to the strength or level of their Affective Filters" (Krashen 1982, p. 31). Krashen places the affective variables into three categories which are: motivation, self-confidence, and anxiety. Referring back to the socio-educational model, Gardner (1985) also saw motivation and anxiety as variables that would impact second language acquisition. In addition to Krashen and Gardner recognizing affective factors as variables in the successful acquisition of a second language, Schumann (1978) also noted that affective variable influence SLA as well as acculturation; however, he 
viewed affective variables to include (1) language shock, (2) culture shock, (3) motivation, (4) and ego permeability. Looking at the studies of Krashen, Gardner, and Schumann, it can be stated that affective variables are dependent on the individual learner. Affective variables are important to consider in SLA in order to understand the individual differences that exist in language learners. An affective variable such as motivation may prevent a learner from reaching their full potential; therefore, it is important to study how these variables may be used toward the learner's advantage. Krashen (1982) states, "acculturation can be viewed as a means of gaining comprehensible input and lowering the filter" (p.45). He saw that acculturation may motivate second language acquisition.

\section{Motivation: Integrative and Instrumental}

Many researchers view motivation and attitude as important factors in determining the rate of success in second language attainment (Gardner \& Lambert, 1959; Spolsky, 1969; Ely, 1986; Oxford \& Shearin, 1994; Dornyei \&Csizer, 1998; Masgoret \& Gardner, 2003; Engin, 2009; Ushioda, 2010). Gardner and Lambert (1959) were some of the earliest researchers to look at the variable of motivation in second language acquisition. They determined that motivation has two different orientations in the field of second language learning, integrative and instrumental. Integrative motivation is "where the aim in language study is to learn more about the language group, or to meet more and different people", whereas, instrumental is "where the reasons reflect the more utilitarian value of linguistic achievement" (Gardner \& Lambert 1959, p. 267). Even though a distinction has been made between integrative and instrumental motivation, it should be noted that instrumental motivation could not exist without a 
certain degree of integrative characteristics. Instrumental motivation involves some interaction with the host community (Gardner 1985). Gardner (1985) continues to explain the dimensions of motivations by stating, "motivation refers to a complex of three characteristics which may or may not be related to a particular orientation. These characteristics are attitudes toward learning the language, desire to learn the language and motivation intensity" (p. 54). Most of Gardner's research has focused on the concept of integrative motivation, possibly because he has identified integrative motivation within the concept of instrumental motivation. In addition, much of Gardner's research has also taken place in Canada, a multicultural society, in which integration is an important issue in developing a second language. A study conducted by Masgoret and Gardner (2003) further confirmed that integrative motivation promotes successful second language acquisition and that motivation is more highly related to second language achievement than any other variable. Figure 2 shows Gardner's concept of integrative motivation by showing the relationship between attitudes and integrativeness and how this influences motivation to impact second language attainment. 
Figure 2. Basic model of the role of aptitude and motivation in second language acquisition. (Gardner 1999)

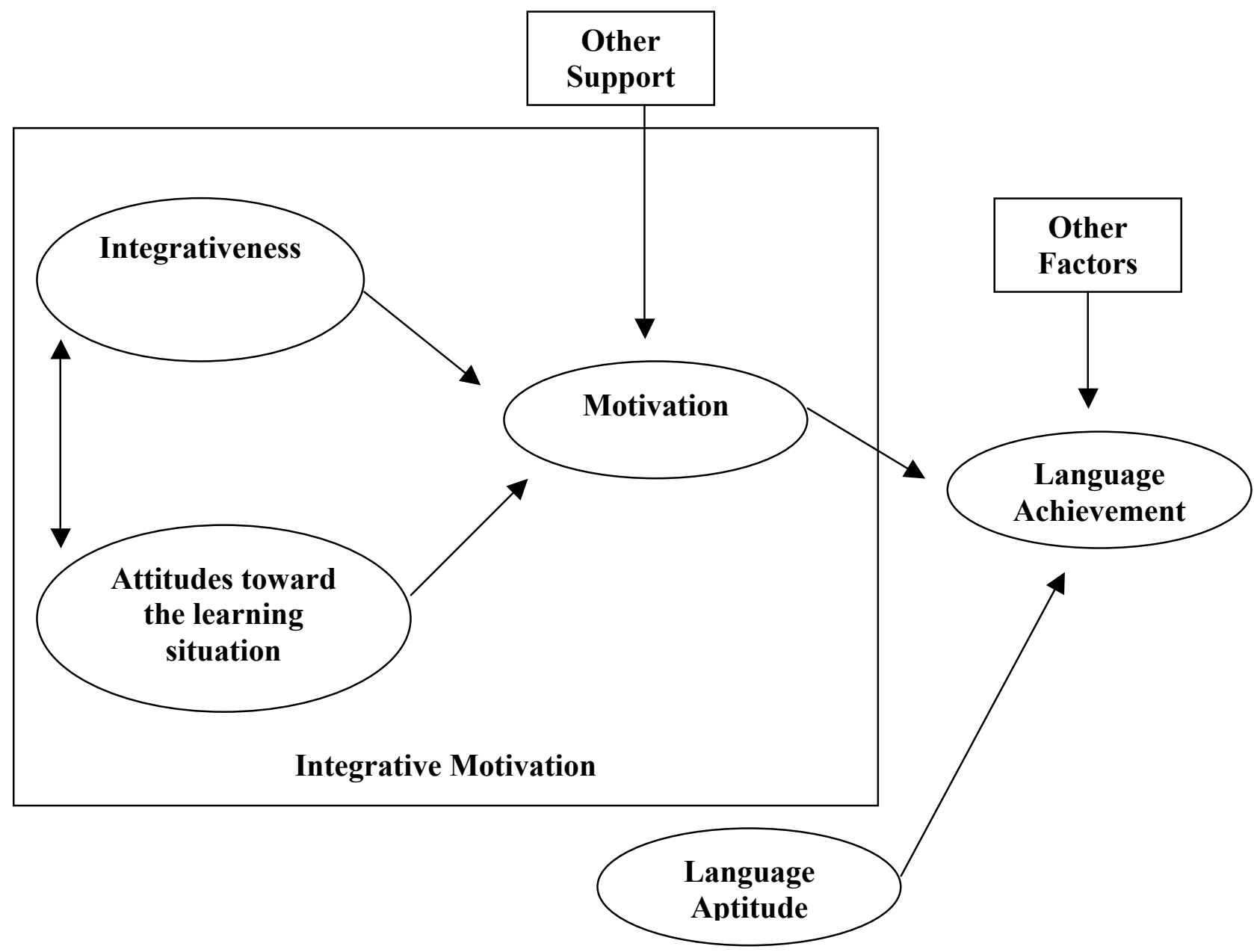

From Figure 2, one can see that a relationship exists between attitudes, acculturation, and motivation. Many researchers have supported this notion that attitude plays an important role in second language learning in that it often has a large impact on motivation. Spolsky (1969) has shown that attitude is an important factor in explaining the proficiency that one achieves in a second language. This is due to the social dimensions involved in acquiring a second language. If a learner's attitude toward the 
target community is positive, it is much more likely for a more successful outcome in acquiring the second language. Therefore, attitudes do not only encompass the feelings towards the learning situation, but also other factors such as society which can have an impact on motivation and ultimately the acquisition of a new language. Gardner and Lambert (1959) state, "we argue that an individual acquiring a second language adopts certain behavior patterns which are characteristic of another cultural group and that his attitudes towards that group will at least partly determine his success in learning the new language" (p. 267). Tremblay and Gardner (1995) add to this discussion on attitude and motivation by suggesting that there are variables that mediate the relationship between language attitudes and motivational behavior such as goal salience, valence, and self efficacy. This shows that personal characteristics related to the learner and the learning situation may have an impact on their motivation. Oxford \& Shearin (1994) also recognize valence through Atkinson's Expectancy-Value Theory and goal salience through the Goal-Setting Theory as important factors to consider in expanding the knowledge of second language motivation.

Many studies have been conducted to support the notion that motivation plays a unique role when learning a second language. Huang's (2008) study looked at motivation and learning strategies in a foreign language-learning context, specifically in a university setting in Taiwan. She found that in second language learning such factors as time, study environment, and effort regulation are important in determining a learner's success. Furthermore, she found that in second language learning "regulated learning matters more than cognitive abilities in the final outcome" (p. 533). This further confirms the notion that motivation can play a determining factor in successful second 
language acquisition since the variable of motivation would be characterized under effort regulation. Many have found issues that may influence the motivation variable in second language learning (Gardner, 1968; Kissau, 2006; Kormos \& Csizer, 2008). All three of these studies found that motivation is often affected by culture and society. Gardner (1968) found that the family impacted one's motivation in learning a second language and that learners were often influenced by their own cultural group. Kissau (2006) also found that one's own society influences how one perceives the new language. However, a study conducted by Kormos and Csizer (2008) found that the English culture was a motive for learning the English language.

The Kormos and Csizer (2008) study leads to the notion that "the learning of a second language (L2) requires cultural as well as linguistic competence. All language live within a cultural context" (Culhane, 2003, p.59). This concept of culture within the language learning context should be explored to gain a better and more complete understanding of the many dimensions and complexities within second language motivation. Culhane $(2003,2004)$ has looked extensively at intercultural interaction and applied it to second language motivation. In Culhane's 2004 study, he looked at how motivation to interact in the target community related to the learner's attitude toward acquiring a second language. The focus of his study was on sojourns or people who spent a period of time in a region where the second language was the medium of communication. He found that "learners with a higher degree of integrative motivation are likely to make more extensive efforts to form bonds with culturally different others when given the opportunity, as a means of learning the linguistic and cultural knowledge needed for sociocultural competence" (p. 59). While Culhane focused on a second 
language context for his study, Csizer and Kormos (2008) looked at the relationship between intercultural contact and language learning motivation in a foreign language context. Their study focused on Hungarian students studying English and German in Hungary. They found that students were willing to study English harder than German, and also had a more positive attitude toward the English language. They related this finding to the fact that English serves as the lingua franca as well as, learners have more contact with English and the English culture through the internet, books, films and magazines. Regardless of the language being studied, Csizer and Kormos found, "students with high levels of motivational intensity engage in various types of intercultural contact more frequently than students who invest less energy into language learning" (p.43). Through the Culhane (2004) and Csizer \& Kormos (2008) studies, it can be concluded that intercultural interaction is very important in the discussion on second language motivation. It further confirms that second language learning should not only be studied in a linguistic context, but also consider the cultural aspects that influence second language achievement regardless of whether it occurs in a second language environment or a foreign language context.

Thus far, the researchers have proven that motivation plays an important role in the acquisition of a second language; however, motivation has been shown that it is not necessarily a constant variable in the discussion on second language acquisition (Gardner, Masgoret, Tennant, \& Mihic, 2004; Shoaib \& Dornyei, 2004). Gardner, Masgoret, Tennant, and Mihic (2004) and Shoaib and Dornyei (2004) all conducted studies looking at motivation changes in second language over time. The Gardner, Masgoret, Tennant, and Mihic (2004) study looked at motivation over a year long course. They found that 
the changes in motivation were not as great as the attitude to the learning situation. Shoaib and Dornyei (2004) looked at the motivation process over a much longer timeframe. Their study took place over two decades to determine if any patterns of motivation emerged over time. They found that the motivation process fluctuates over time. They also reported six patterns that emerged over these two decades: (1) maturation and gradually increasing interest, (2) stand-still period, (3) moving into a new life phase, (4) internalizing external goals and imported visions, (5) relationship with a significant other, and (6) time spent in the host environment. These two studies, particularly the Shoaib and Dornyei study, show that changes do occur in motivation over time and that the social experience that one encounters over time influences one's motivational transformation. Self- Determination Theory

One theory that has made its way into the discussion on second language motivation is self-determination theory. Deci and Ryan (1985) introduced the selfdetermination theory to distinguish the different types of motivation: intrinsic and extrinsic. Ryan and Deci (2000) state that "intrinsic motivation which refers to doing something because it is inherently interesting or enjoyable, and extrinsic motivation, which refers to doing something because it leads to a separable outcome" (p.55). They have found that intrinsic motivation "results in high quality learning and creativity" (p.55). Another way of thinking about extrinsic motivation is to relate it to motivation with an instrumental orientation. Noels, Pelletier, Clement, and Vallerand (2000) give a more clear definition of extrinsic motivation in relation to second language learning. They state, "extrinsic motivation (EM) are those actions carried out to achieve some 
instrumental end, such as earning a reward or avoiding a punishment” (p.39). In their study, they found that intrinsic motivation and extrinsic motivation should be included in the discussion on motivation in second language learning. It was found that those learners whose motivation was internalized or self-determined were more comfortable in the language learning process. Therefore, the Noels, Pelletier, Clement, and Vallerand (2000) helped to determine that intrinsic motivation may in fact result in better learning as suggested by Ryan and Deci (2000).

\section{The L2 Motivational Self System}

Dornyei (2005) recently proposed the L2 motivational self system to further the research in motivation in second language learning. The L2 motivational self system came about in response to limitations that Dornyei found with the instrumental versus integrative motivational orientations (Dornyei 2009a). The L2 motivational self system takes a whole-person perspective which Dornyei found superior to the two distinctive orientations of Gardner. The L2 Motivational Self System is comprised of three parts: (1) the ideal L2 self, (2) the ought-to L2 self, and the L2 Learning Experience. Dornyei (2009a) explains the ideal self and the ought to self with the following:

The ideal self refers to the representation of the attributes that one would ideally like to possess (i.e. representation of hopes, aspirations, or wishes), while the ought self refers to the representation of attributes that one believes one ought to possess (i.e. representation of someone else's sense of duties, obligations, or moral responsibilities) and which therefore may bear little resemblance to one's own desires or wishes. (p.13) 
The ideal self and the ought self are important parts of understanding the motivational process in language learning because as Dornyei (2009a) explains, "language learning is a sustained and often tedious process with lots of temporary ups and downs, and I felt that the secret of successful learners was their possession of a superordinate vision that kept them on track" (p.25).

Many recent studies have taken into account this new notion of the L2 Motivational Self System (Csizer \& Dornyei, 2005a; Csizer \& Dornyei, 2005b; Kormos \& Csizer, 2008; Dornyei, 2009b; Dornyei, 2010). The view that learners have of themselves and their learning process often influences their motivation in learning the language. Kormos and Csizer (2008) found that the students attitudes toward language learning and their ideal L2 self are key to determining their efforts. The studies of Csizer and Dornyei (2005a) and Dornyei (2010) both found a direct connection between motivation and the ideal L2 self. The most motivated students were found to have developed an ideal L2 self. All of these studies suggest that one way of taking control of the motivational aspect of second language learning, it is important for learners to construct an ideal L2 self.

\section{Conclusion}

The discussion on motivation in second language acquisition has shown that it is a very important variable to consider when examining second language achievement. Most of the research has supported the notion that one's social environment plays a vital role in influencing the motivational factor of second language learning. It is important to explore this social environment more to gain a greater understanding of the individual learner's motivational process of language learning. 
This section of the literature review has taken into account acculturation and motivation, instrumental motivation and integrative motivation, self-determination theory, and the L2 Motivational Self System. The research in this area has progressed with new ideas on the impacts of motivation on L2 learning and also issues that influence a learner's motivational process. It is important to keep this discussion going in order for new ideas to be presented.

This study expanded on the concept of the role of the social environment in second language learning. While most of these studies have not distinguished between the type of learner in terms of age, setting, or reasoning, this study took all of these into account. It is hoped that this study will shed new light on the social aspects of the motivational process in second language acquisition and find a place within the research already presented. 


\section{Chapter 3: Methodology \\ Introduction}

This study had three main goals: to determine the effect of children on the parent's acculturation level, to determine the effect of children on the parent's motivation to learn English, and to explore the effect of the English language use on the family structure of these immigrant families. Both descriptive and inferential statistics were used to examine these goals. This section describes the population/sample of the study, the procedure and instrument used, the pilot study, and the method of analysis used.

\section{Population/Sample}

The sampling of participants that were chosen for the main study were completely anonymous and randomly selected. It was required that the participant be an adult over the age of eighteen with a Hispanic background. Age, gender, community, education, job, or family status were not determining factors for participants to take part in the study. For access to this population, the researcher contacted a director of multicultural outreach within the public school district in Denver, Colorado who made these surveys available at multicultural outreach events. According to the Pew Research Center (2011), the population of Hispanics in the Denver-Boulder, CO area is 609,000 which is $23.2 \%$ of the population. Within the Denver Public Schools, $58 \%$ of the students are Hispanic and 39\% are Spanish-speaking (Denver Public Schools, 2012). The public school district of Denver, Colorado was chosen for this study due to the large number of Hispanic families in the area as well as a well-developed community outreach program for these families within the school system. 
For this study, 400 surveys were sent to the director of multicultural outreach of the public schools in Denver, Colorado to be distributed at outreach events. Out of the 400 surveys sent, 249 surveys were received. Out of the 249 surveys received, 173 were valid and completed in full, which was about $43 \%$ of the total surveys (see Table 2).

Table 2. Sample Size

\begin{tabular}{|c|c|c|c|}
\hline $\begin{array}{c}\text { Total Number of } \\
\text { Distributed Surveys }\end{array}$ & $\begin{array}{c}\text { Total Number of } \\
\text { Surveys Received }\end{array}$ & $\begin{array}{c}\text { Total Number of } \\
\text { Valid Surveys } \\
\text { Received }\end{array}$ & $\begin{array}{c}\text { Sample Size } \\
\text { (n) }\end{array}$ \\
\hline 400 & 249 & 173 & $173(43 \%)$ \\
\hline
\end{tabular}

The demographics of this population provide a better understanding of the background of the participants. While many came from similar backgrounds, there were also differences that existed between the individuals in respect to origin, gender, age, education, years in the United States, income, living situation, level of English, and the number of children. Table 3 and Figures 3-13 show the percentages of each demographic group. The majority of participants identified their country of origin as Mexico making up $98 \%$; whereas, El Salvador was comprised of $2 \%$ of the population. Within Mexico, $25 \%$ came from the region of Chihuahua, Mexico. The gender of the participants was somewhat unequal with $76 \%$ female and $24 \%$ male. The age of the participants consisted of $10 \% 25$ years or younger, $35 \% 26$ years to 35 years, $44 \% 36$ years to 45 years, $7 \% 46$ years to 50 years, and $4 \% 51$ years or older. The highest level education completed included $1 \%$ no education, $2 \%$ less than elementary school, $12 \%$ elementary school, $9 \%$ middle school, $53 \%$ high school, $17 \%$ some university, $5 \%$ university, and $1 \%$ graduate school. The years in the United States varied with 2\% less than one year, 3\% one to five 
years, $24 \%$ five to ten years, and $71 \%$ more than 10 years. The household income of the participants consisted of $20 \%$ making less than $\$ 10,000,25 \%$ making $\$ 10,000$ to $\$ 19,999,27 \%$ making $\$ 20,000$ to $\$ 29,999,15 \%$ making $\$ 30,000$ to $\$ 39,999,7 \%$ making $\$ 40,000$ to $\$ 49,999$, and $6 \%$ making $\$ 50,000$ or more. The majority of participants lived in a household consisting of only their spouse and children at $46 \%$; however, $32 \%$ lived with extended family members, $12 \%$ lived only with their children, $6 \%$ lived only with their spouse, and $4 \%$ lived with nonfamily members. The level of the participants' English varied with $42 \%$ rating themselves as intermediate, $40 \%$ as beginner, $9 \%$ as advanced, and 9\% having no English language ability. In terms of studying English, 43\% are currently studying English, while 57\% are not studying English. Out of all the participants in this sample size, $89 \%$ have children, while $11 \%$ do not have children. 
Table 3. Demographics of Participants

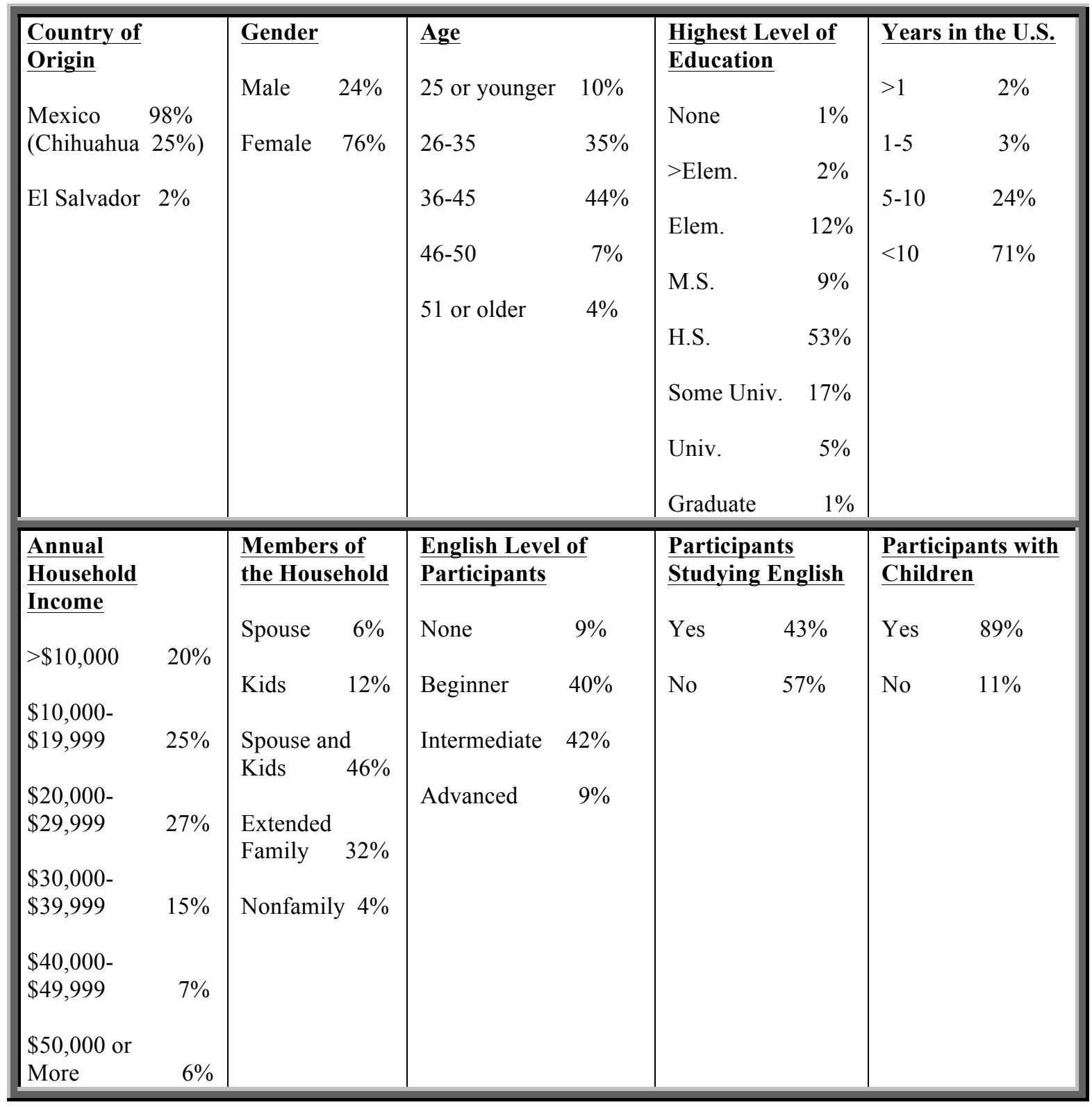


Figure 3. Demographics: country of origin.

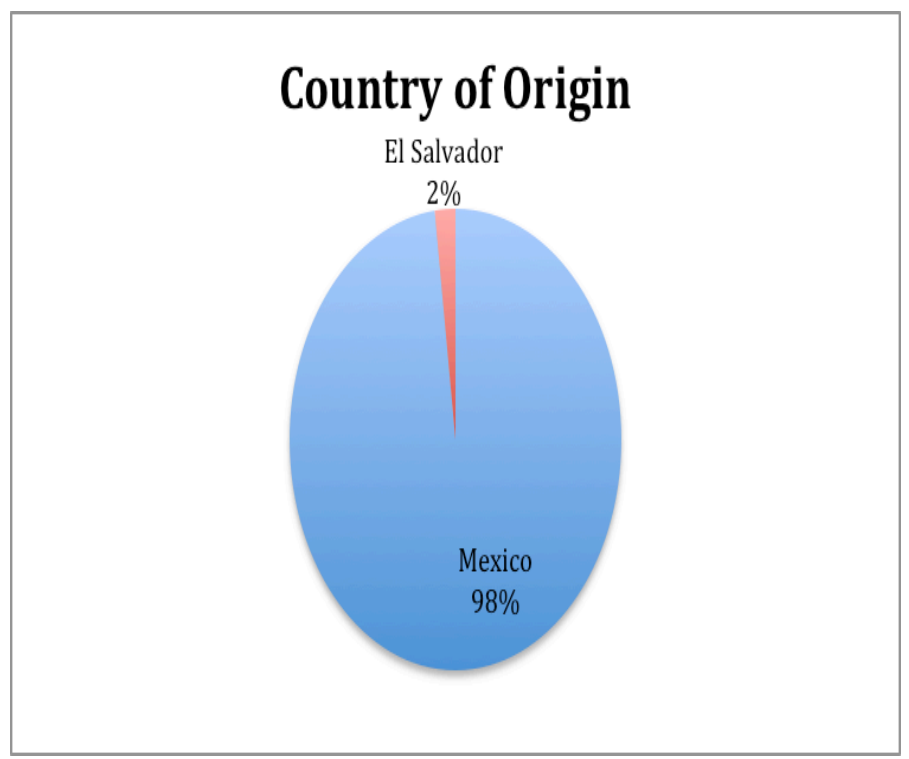

Figure 4. Demographics: origin within Mexico.




Figure 5. Demographics: gender of participants.

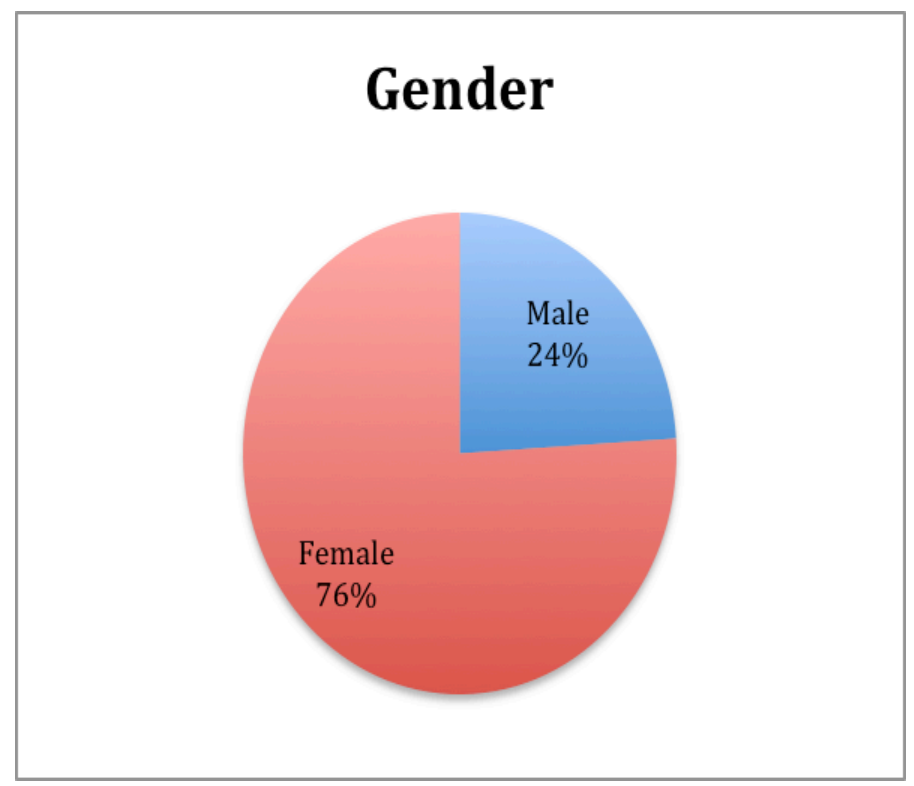

Figure 6. Demographics: age of participants.

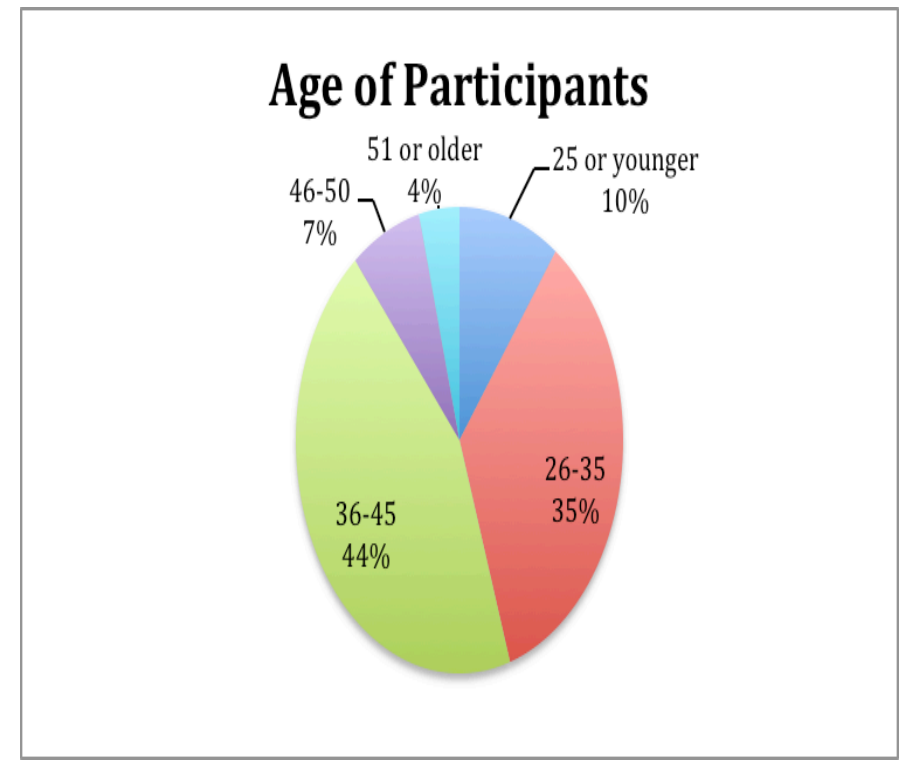


Figure 7. Demographics: highest level of education completed.

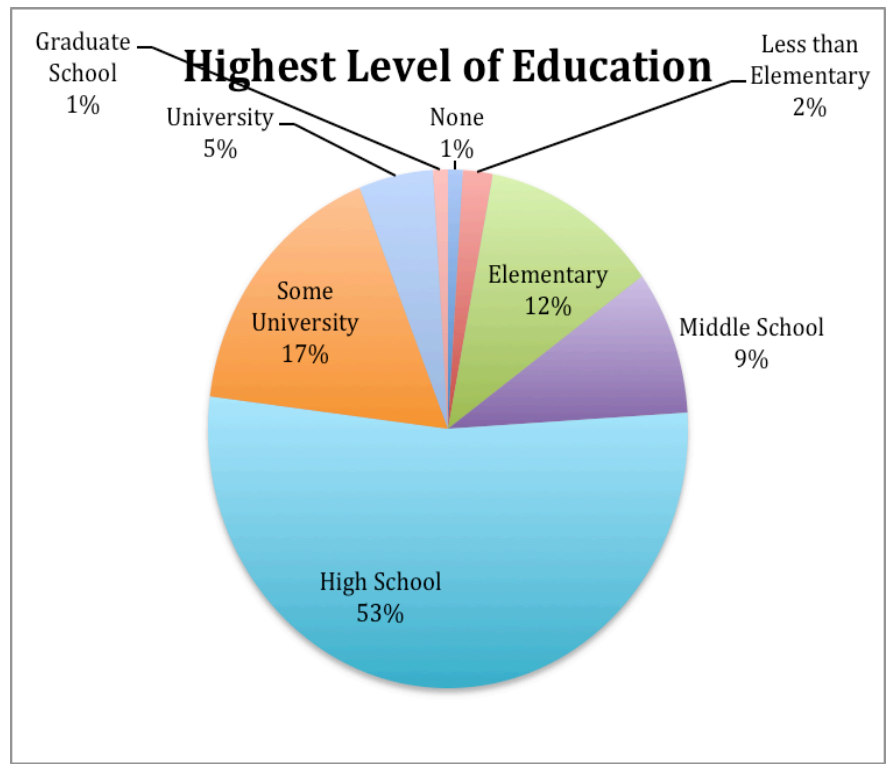

Figure 8. Demographics: years in the United States.

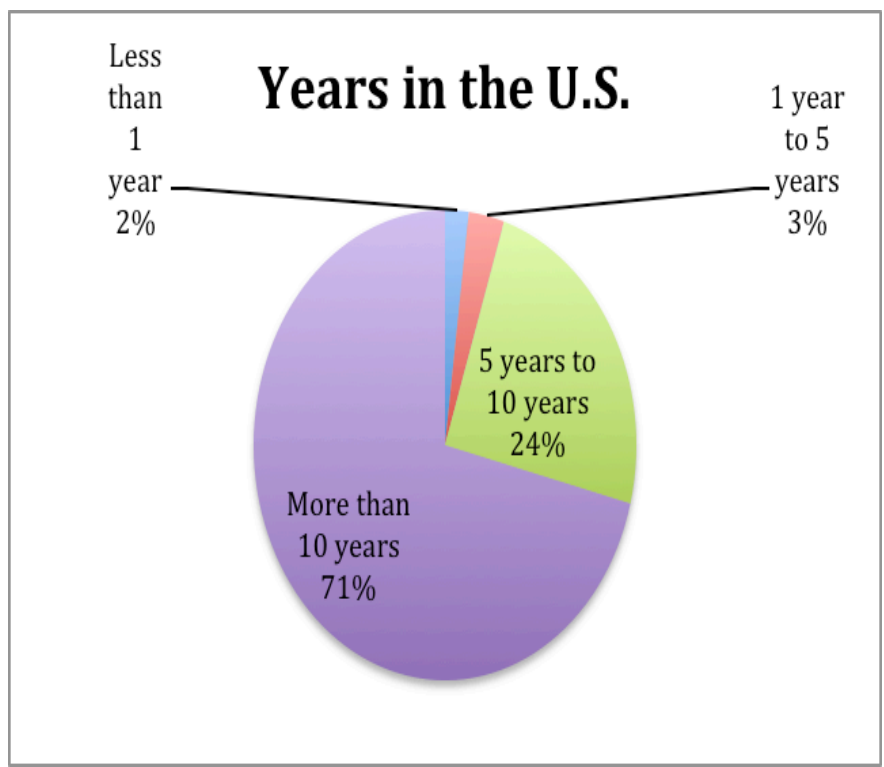


Figure 9. Demographics: annual household income.



Figure 10. Demographics: members of the household.

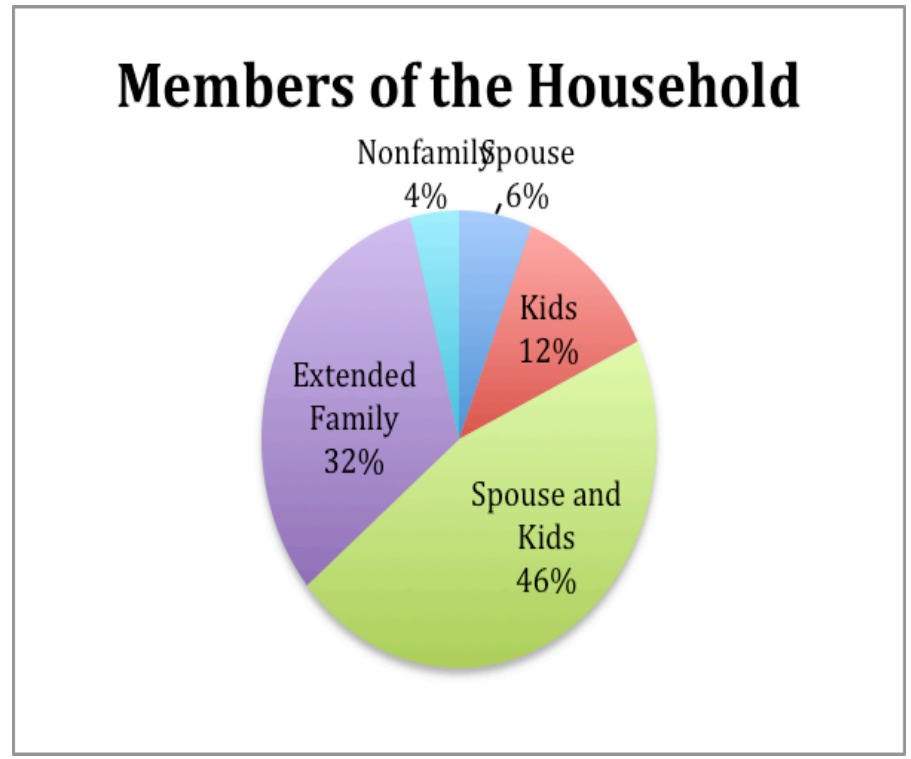


Figure 11. Demographics: English language level of participants.

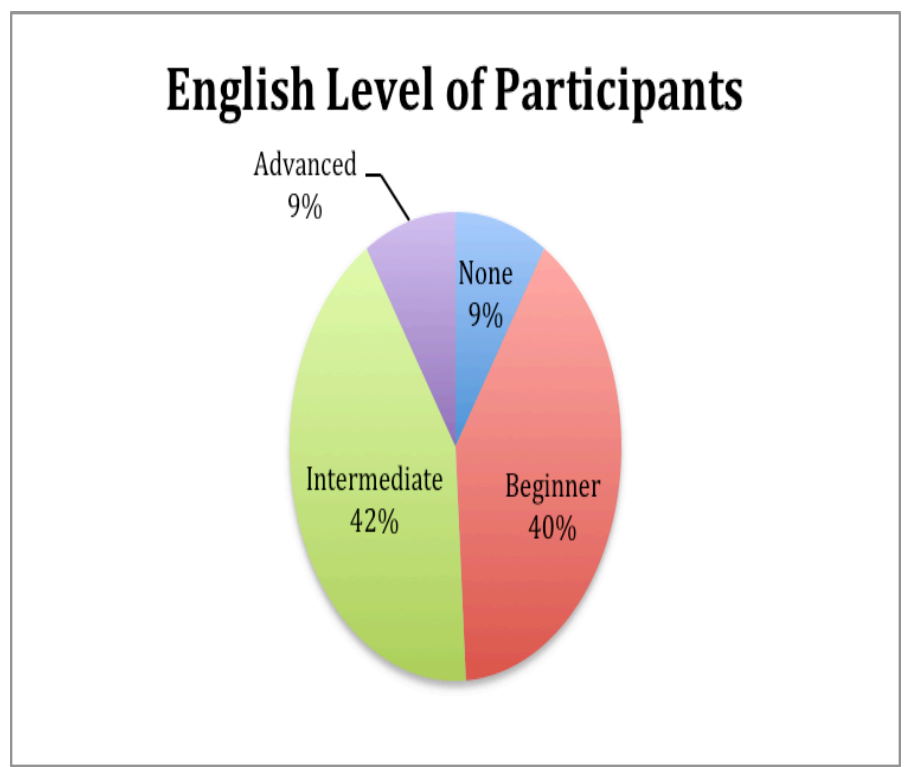

Figure 12. Demographics: participants currently studying English.

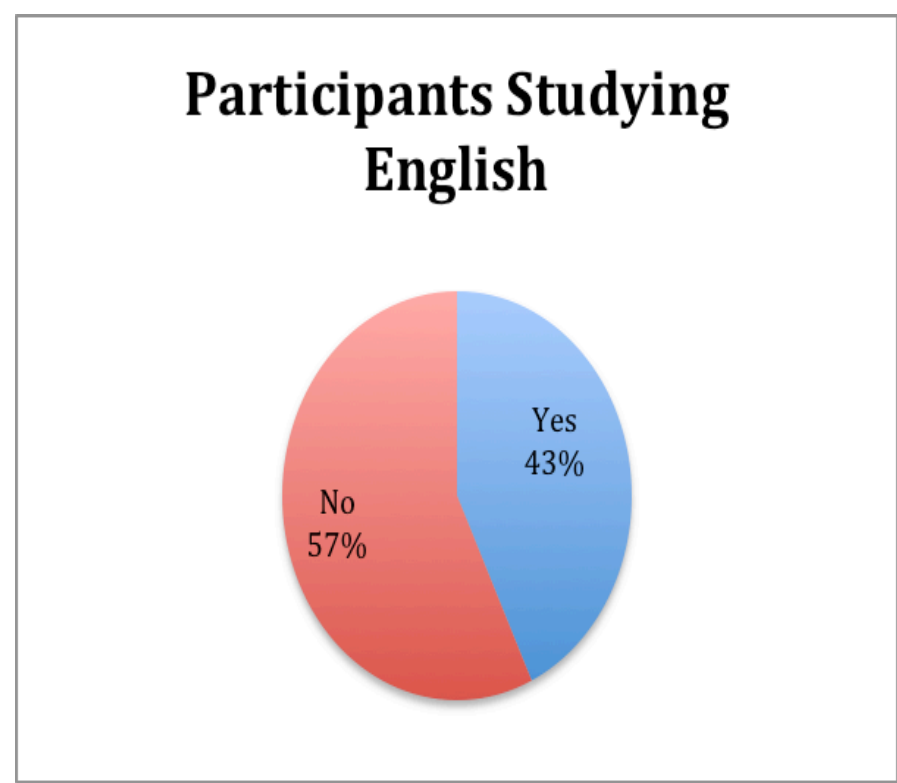


Figure 13. Demographics: participants with children.

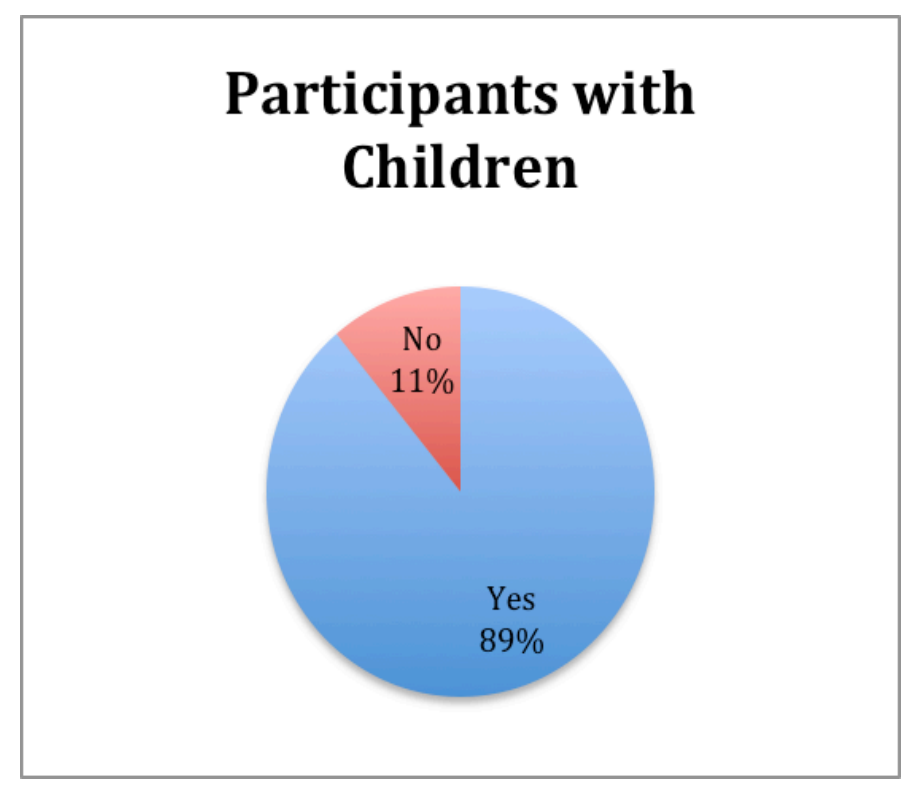

The children-related demographic characteristics of the participants served as the independent variables of the statistical analysis of this study. These included number of children, age of children, gender of children, and English language level of children. Table 4 shows the frequencies of these demographics and Figures 14-17 also illustrate these numbers. For this sample population, no one had more than 5 children. The majority had two children, which consisted of 60 participants, 40 participants had three children, 26 participants had four children, 20 participants had one child, 19 participants had no children, and 8 participants had five children. In terms of the age of the children, 71 had children 12 years or younger, 32 had children older than 12 years, and 51 had children in both age ranges. Thirty-seven participants had only boys, 37 participants had only girls, and 80 participants had both boys and girls. For the English language level of the children, the majority had children with an advanced level of English making up 92 
participants, 33 participants had children at the intermediate level, 18 participants had children at the beginner level, and 11 participants had children at various levels.

Table 4. Children-Related Demographic Frequencies

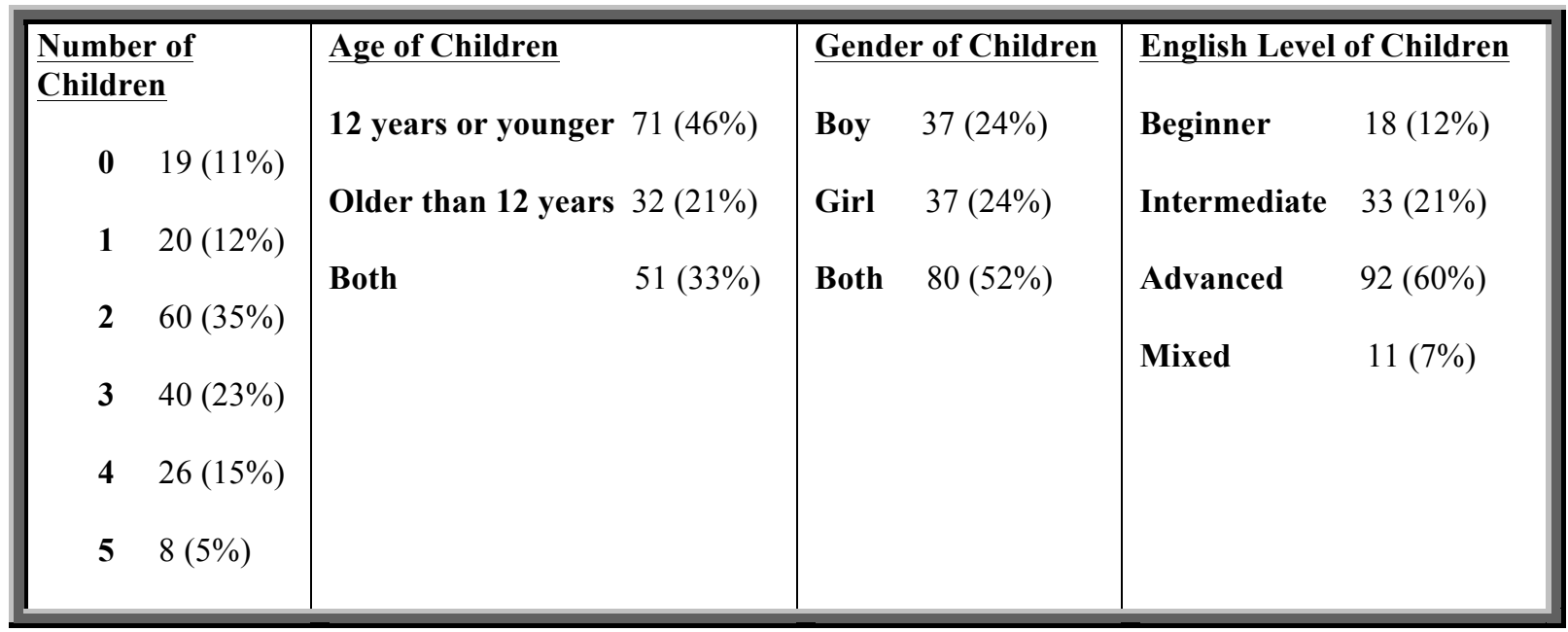

Figure 14. Demographics: number of children.

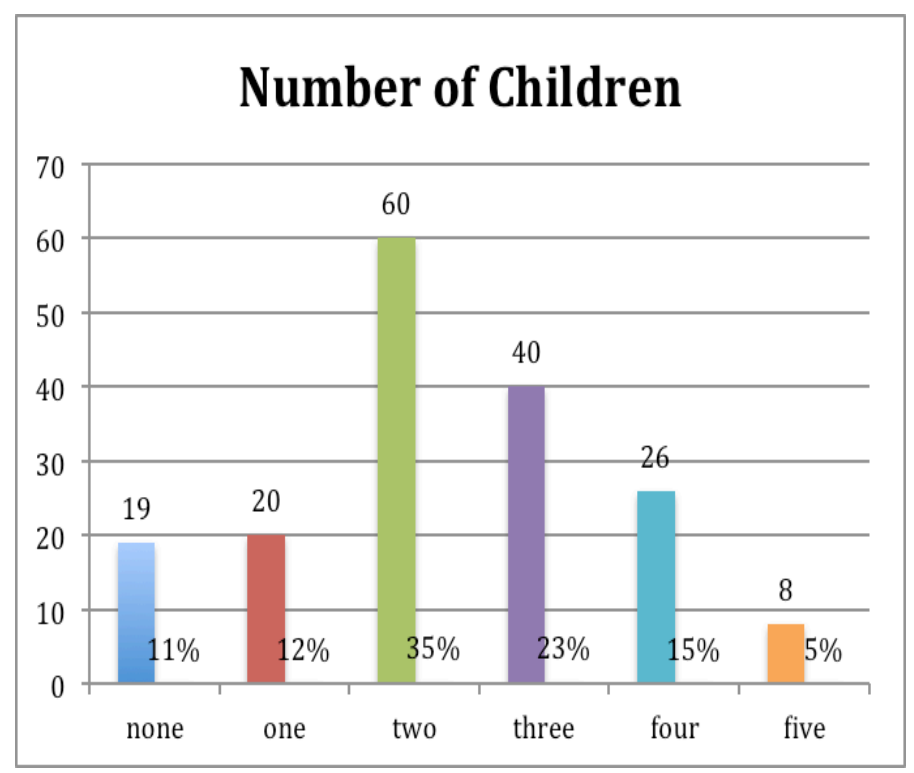


Figure 15. Demographics: age of children.

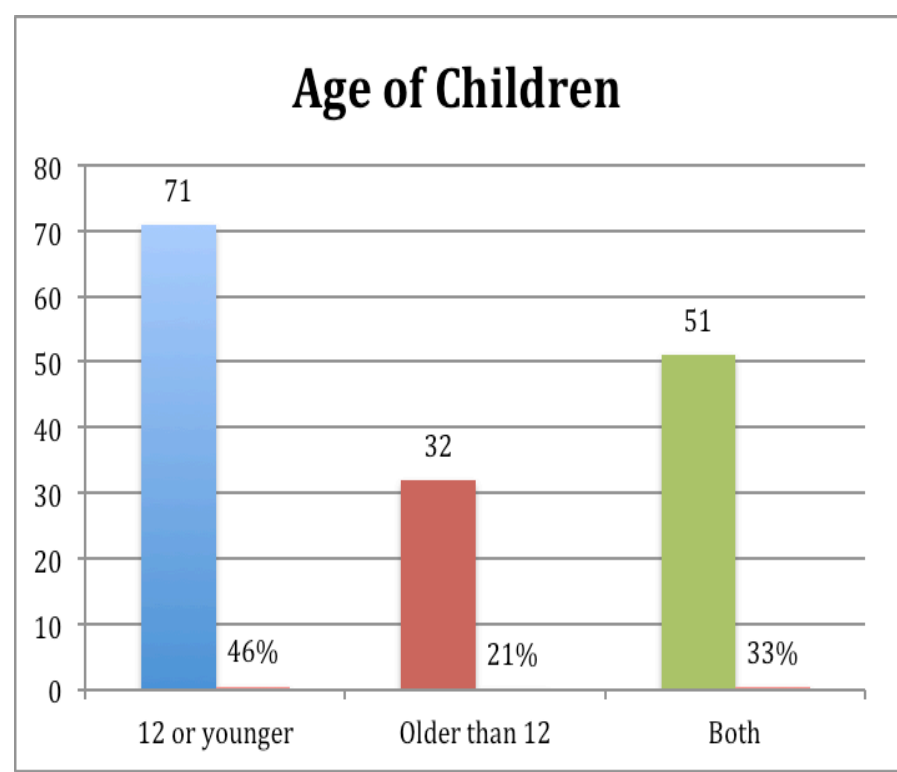

Figure 16. Demographics: gender of children.

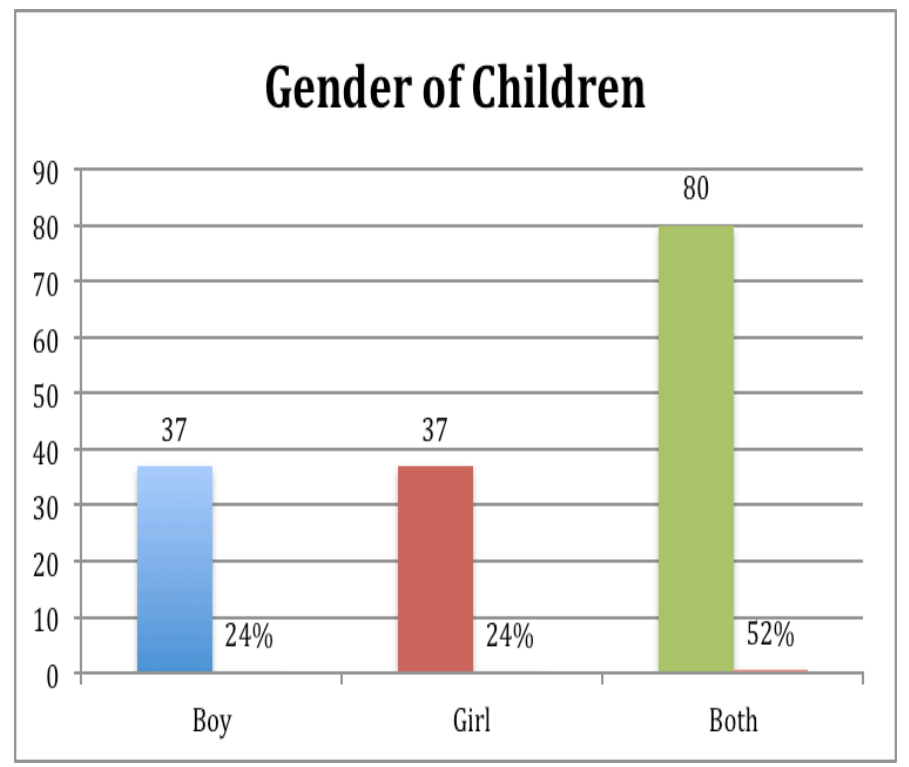


Figure 17. Demographics: English language level of children.

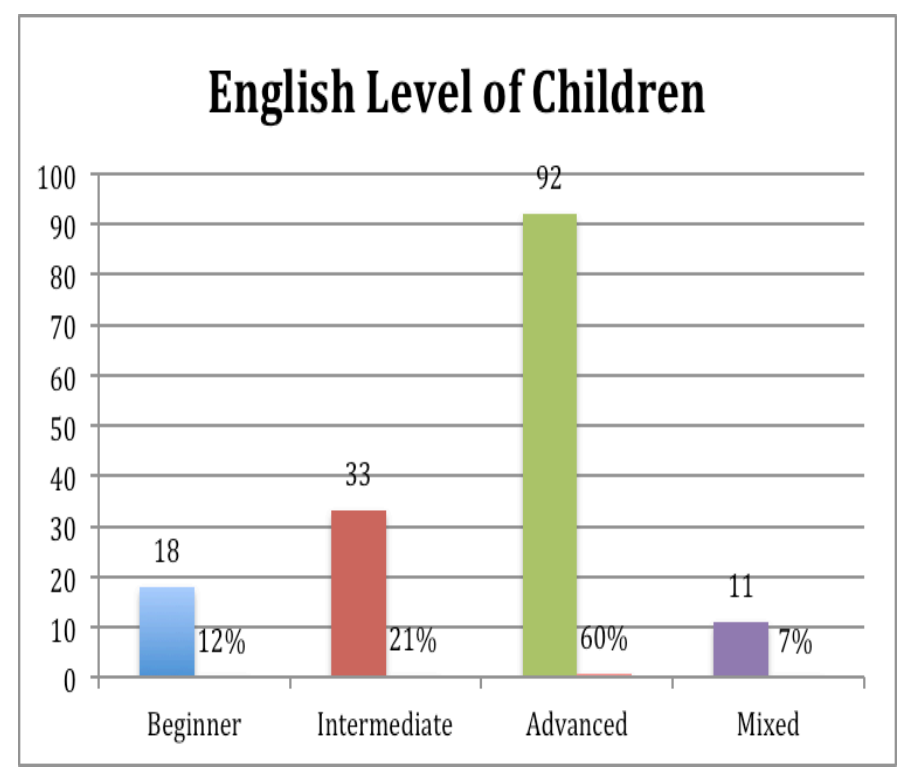

Procedure/Instrumentation

A survey and qualitative questionnaire was used for this study. The survey and questionnaire was mailed to the director of multicultural outreach for disbursement. The survey consisted of three parts with the addition of the qualitative questions. The first part of the survey was comprised of demographic factors, which include demographic characteristics of the participant as well as demographics related to their children. The second part of the survey included an acculturation scale, which measured the acculturation level of the participant. The third part of the survey was a motivational assessment scale. This scale measured the participants' motivation to learn the English language. The qualitative questionnaire consisted of three questions that the participants answered based on their own personal experience. 
The demographic section of the survey consisted of background demographic characteristics that provided a context of the participants taking part in the study, as well as, children-related demographic factors. The demographic factors in this survey included: country of origin, gender, age, years in the United States, annual household income, members of the household, English language level, studying of the English language, number of children, age of children, gender of children, and English language level of children. The children-related demographic factors (number of children, age of children, gender of children, and English language level of children) were used in the statistical analysis part of this study. The number of children was operationalized into seven groups $(0,1,2,3,4,5$, more than 5$)$. The age of children was operationalized into three groups (12 years or younger, older than 12 years, both). The gender of children was operationalized into three groups (male, female, both). The English language level of children was operationalized into three groups (beginner, intermediate, advanced).

The second part of the survey consisted of the acculturation rate scale. Two acculturation scales were reviewed for validity before the researcher created the acculturation scale for this study, The Short Acculturation Scale for Hispanics (Marin et al., 1987) and The Acculturation Rating Scale for Mexican Americans-II (Cuellar, Arnold, \& Maldonaldo, 1995). Due to the fact that the participants in the study are very limited in their proficiency of the English language, many of the questions on these already established acculturation scales had to be adapted to correspond with the participants in this study and their situation. The Short Acculturation Scale for Hispanics (Marin et al., 1987) is a twelve item scale that looks at the Hispanic experience by accounting for their use of English and Spanish, in general and in their personal lives, in 
both the past and the present. In addition, it looks at their social environment in terms of Latino versus American. The Acculturation Rating Scale for Mexican Americans-II (Cuellar, Arnold, \& Maldonado, 1995) is a much longer scale that focuses solely on Mexican Americans. It is a thirty-item scale that rates their association with English versus Spanish as well as the culture that they associate and identify with the most.

The acculturation scale for this study was a twelve-item scale. The first six items rated the frequency of English and Spanish use in different social situations. The last six items rated experiences that may be unique to these particular participants and their situation in the United States culture that would affect their acculturation level. These included experiences with their children and their children's schools, as well as their association and identity within the American culture. In the likert-type scale, the items were organized to either relate to the Hispanic culture or the American culture. Each item was rated on a five point likert-type scale based on the frequency of the participants experience: $1=$ Never, $2=$ Very Little, $3=$ Sometimes, $4=$ Frequently, $5=$ Almost all the time. Item numbers $1,3,5,7,9$, and 11 relate to the Hispanic culture; whereas, item numbers $2,4,6,8,10$, and 12 relate to the American culture. For participants with no children, item numbers $3,4,7$, and 8 were removed for their acculturation scale.

The third part of the survey was comprised of the Motivation/Attitude likert-type scale. This scale was based on a portion of Gardner's (1985) Attitude/Motivation Test Battery(AMTB). The motivation/attitude scale was adapted from the last part of Gardner's (1985) AMTB in order to create a feasible scale for the participants in this study. Gardner's (1985) AMTB was created to measure the attitude and motivation of English-speaking students learning French in Canada. Due to the lengthy nature of the 
original AMTB and its orientation to young English speaking students learning French, it cannot be used for this study. However, the researcher created a scale that addressed many of the same concepts that would measure motivation and attitude to the English language for this particular group of participants. Each item in this scale measured the motivation or attitude toward the English language or learning the English language. The participant marked the response that best represented their attitude or motivation. The motivation/attitude toward the English language was determined based on their responses.

The final part of the survey consisted of the qualitative questionnaire. This section allowed the participant to provide personal reflection on their experience in the United States culture with the English language and how it has impacted their life. It consisted of three questions. Question one allowed them to reflect on their motivating factors for learning English. Question two asked them how their family roles have been affected by the English language. Question three allowed them to discuss how their child's English language use has impacted their family's Spanish use and cultural customs. This qualitative section aimed to give a more personal and human voice to the study.

\section{Translation of the Survey and Questionnaire}

The survey and questionnaire was provided to the participants in Spanish. The researcher who holds a Bachelor of Arts degree in the Spanish language first translated the survey and questionnaire. It was then reviewed by a professional in the Spanish language and Hispanic culture. The reviewer of the translations was raised in a Hispanic culture as well as holds a Bachelor of Arts degree and Master of Arts degree in the 
Spanish language. She ensured that the Spanish translations were accurate and the survey was in no way offensive or hurtful to the Hispanic culture.

IRB Approval

Following approval from West Virginia University’s Institutional Review Board (IRB), the surveys and cover letters were sent out for the study. The pilot study was conducted first. Once reliability and validity of the survey was established from the pilot study, the surveys and cover letters were sent to Denver, Colorado for the main study to occur.

\section{Pilot Study}

Due to the fact that the acculturation scale was adapted from Marin et. al. (1987) and Cuellar, Arnold, and Maldonaldo (1995) and the motivation/attitude scale was adapted from Gardner (1985) in order to accommodate the participants for this study and have not been used for any previous studies, it was necessary to conduct a pilot study to ensure validity and reliability of the survey. The pilot study allowed for the researcher to observe any problems with the survey that should be changed before the main study was conducted. For the pilot study, twenty-five surveys were sent to an ESL teacher in the local public schools who sent them with her Spanish-speaking students for their parents to complete. Out of the twenty-five surveys sent out, seven valid surveys were received. After an analysis of the returned surveys, there were no problems found with the survey; therefore, corrections were not needed for the main study. The pilot study data was not used with the main study due the differences in populations between the pilot study and main study. The pilot study was used solely as a test for the validity and reliability of the survey. 


\section{Analysis}

The goal of this study was to determine the impact that children have on their immigrant parents, particularly in terms of acculturation and motivation in English language learning. Table 5 and table 6 show the independent variables and dependent variables for this study. One-way ANOVAs were used for the statistics part of this study. For research questions one and two, 8 one-way ANOVAs were conducted. Four of the one-way ANOVAs were used to show the impact of the independent variables (number of children, age of children, gender of children, and English language level of children) on the dependent variable (immigrant parent's acculturation level). The remaining 4 oneway ANOVAs were used to show the impact of the independent variables (number of children, age of children, gender of children, and English language level of children) on the dependent variable (immigrant parent's motivation to learn English). Figures 18 and 19 illustrate the 8 one-way ANOVAs that were used in this study. Tukey post hoc tests were used to show the differences in the level of significance between the levels of the demographic characteristics. For the qualitative questions, thematic analysis was used. The response from the qualitative questions were analyzed for similar responses or patterns that were then placed into specific themes. 
Table 5. Independent Variables

\begin{tabular}{|l|}
\hline \multicolumn{1}{|c|}{ Independent Variables } \\
\hline Number of Children \\
\hline Age of Children \\
\hline Gender of Children \\
\hline English Language Level of Children \\
\hline
\end{tabular}

Table 6. Dependent Variables

\begin{tabular}{|l|}
\hline \multicolumn{1}{|c|}{ Dependent Variables } \\
\hline Parent's Acculturation Level \\
\hline Parent's Motivation/Attitude Toward English \\
\hline
\end{tabular}

Figure 18. One-way ANOVAs: parent's level of acculturation.

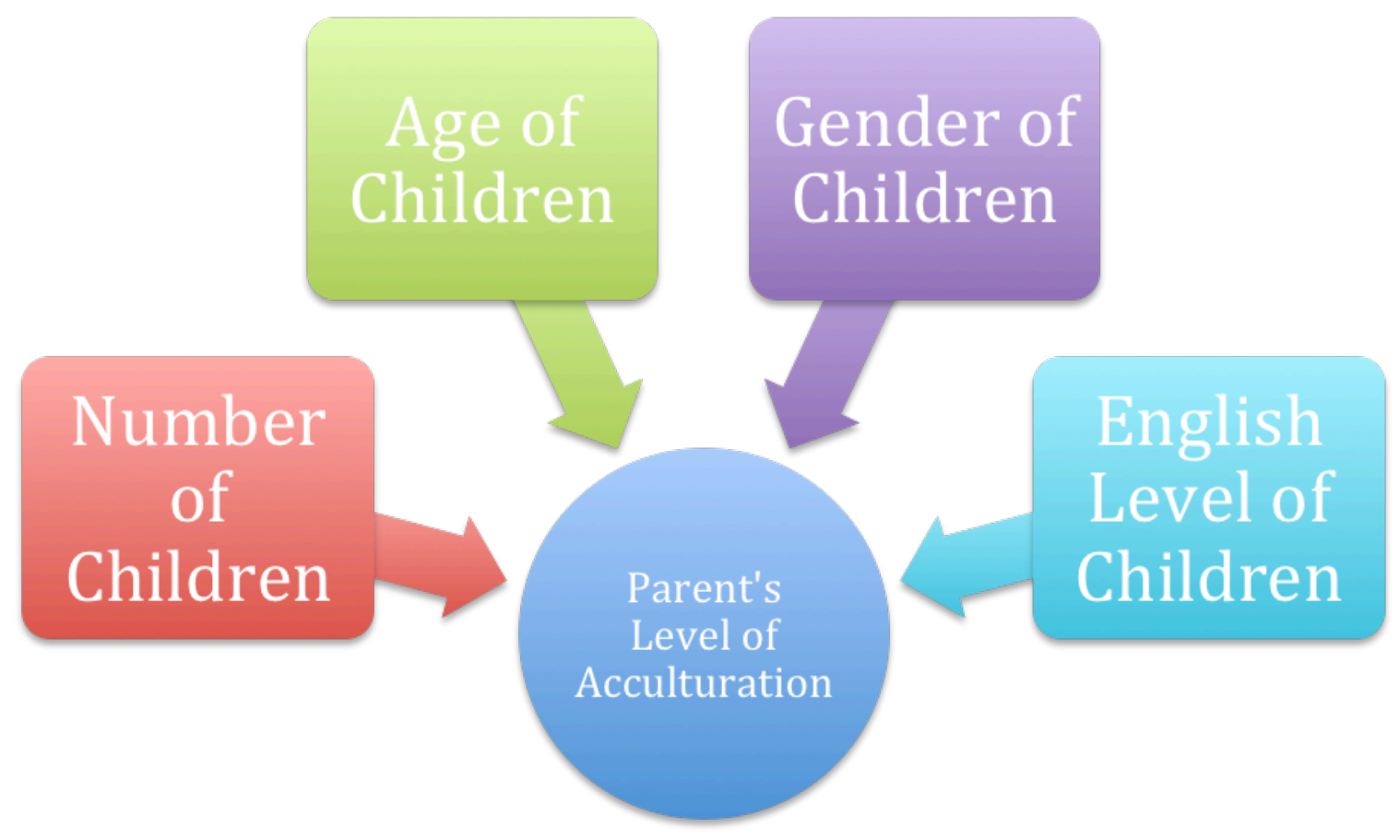


Figure 19. One-Way ANOVAs: parent's motivation toward the English language.

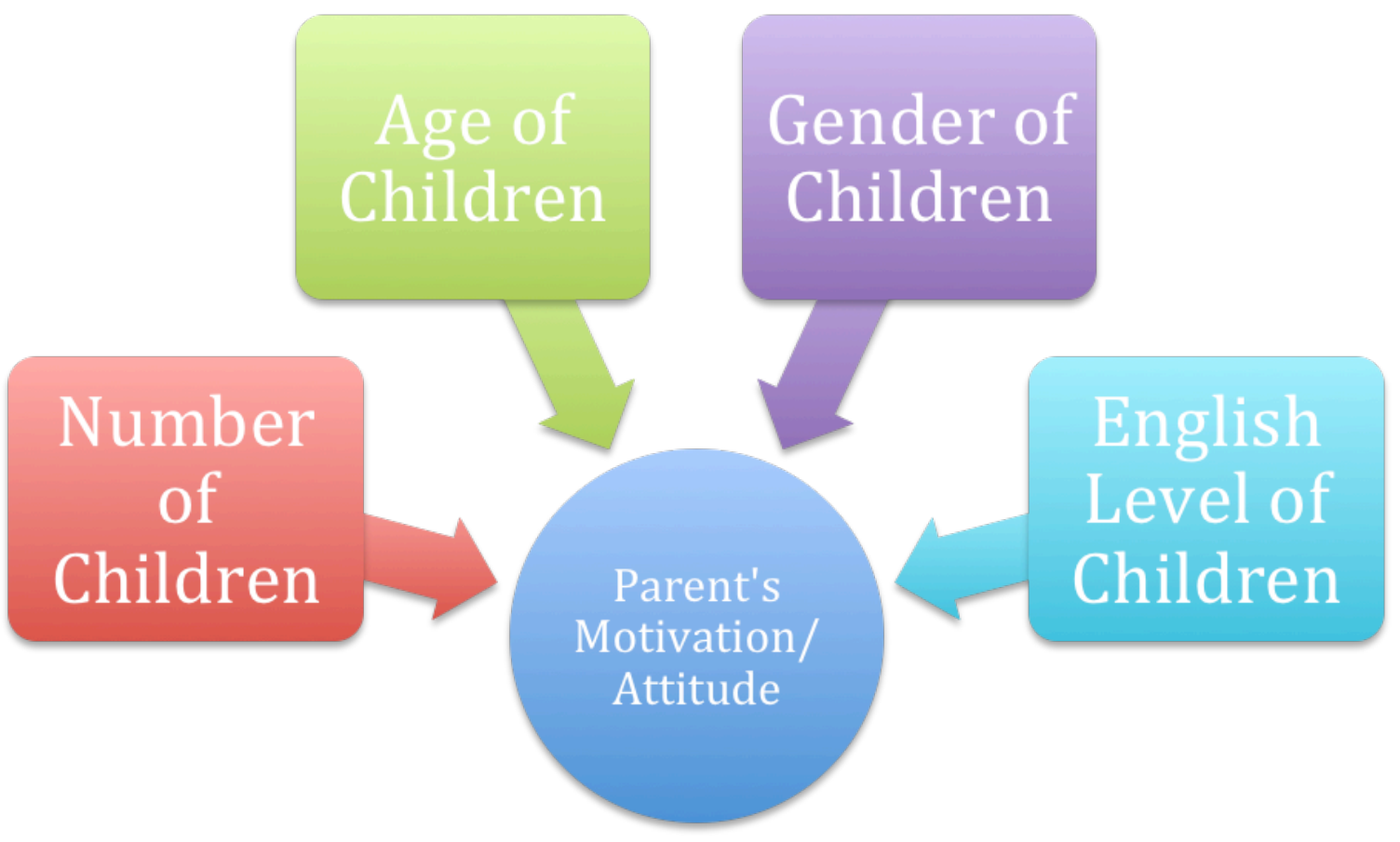




\section{Chapter 4: Results and Analysis}

Introduction

This chapter looks at the results of the statistics as well as the qualitative analysis

of the survey. Four main research questions and eleven hypotheses were used to guide this study:

\section{How are children impacting the acculturation of the immigrant parent in the}

\section{United States?}

$\mathrm{Q}_{1}$ : Does the number of children have an effect on the immigrant parent's acculturation level?

$\mathrm{H}_{1}$ : There is no significant effect of the number of children on the immigrant parent's acculturation level.

$\mathrm{Q}_{2}$ : Does the age of children have an effect on the immigrant parent's acculturation level?

$\mathrm{H}_{2}$ : There is no significant effect of the age of children on the immigrant parent's acculturation level.

$\mathrm{Q}_{3}$ : Does the gender of children have an effect on the immigrant parent's acculturation level?

$\mathrm{H}_{3}$ : There is no significant effect of the gender of children on the immigrant parent's acculturation level.

Q4: Does the English language level of children have an effect on the immigrant parent's acculturation level?

$\mathrm{H}_{4}$ : There is no significant effect of the English language level of children on the immigrant parent's acculturation level.

\section{How are children impacting the immigrant parent's motivation to learn the}

\section{English language in the United States?}

$Q_{1}$ : Does the number of children have an effect on the immigrant parent's motivation to learn English?

$\mathrm{H}_{5}$ : There is no significant effect of the number of children on the immigrant parent's motivation to learn the English language. 
$\mathrm{Q}_{2}$ : Does the age of children have an effect on the immigrant parent's motivation to learn English?

$\mathrm{H}_{6}$ : There is no significant effect of the age of children on the immigrant parent's motivation to learn the English language.

$\mathrm{Q}_{3}$ : Does the gender of children have an effect on the immigrant parent's motivation to learn English?

$\mathrm{H}_{7}$ : There is no significant effect of the gender of children on the immigrant parent's motivation to learn the English language.

$\mathrm{Q}_{4}$ : Does the English language level of children have an effect on the immigrant parent's motivation to learn English?

$\mathrm{H}_{8}$ : There is no significant effect of the English language level of the children on the immigrant parent's motivation to learn the English language.

\section{What are the main motivating factors for learning the English language?}

$\mathrm{H}_{9}$ : Motivation to learn the English language will include both integrative and instrumental factors.

\section{How have the children's English language learning affected the family unit in}

\section{the United States?}

$\mathrm{Q}_{1}$ : How have the roles within the family been affected by the English language?

$\mathrm{H}_{10}$ : Children are now taking a more active and responsible role within the family because of the English language.

$\mathrm{Q}_{2}$ : How have the children's English language learning impacted the practice of the native language and culture within the family?

$\mathrm{H}_{11}$ : The children's English language learning has reduced the presence and importance of the native language and culture within the family.

Questions one and two were addressed quantitatively and questions three and four were addressed qualitatively. This chapter covers four parts: the acculturation level of immigrant parents and the impact of demographic factors, the motivation of immigrant parents toward learning English and the impact of demographic factors, an analysis of the results pertaining to the research questions and hypotheses, and the qualitative analysis. By looking at the results this way, one can have a clearer image of what the results are 
really saying. It is important to understand the mean and standard deviation of each statistical test as well as the level of significance. It is also beneficial to have a thorough analysis of the qualitative data to understand the results as a whole. For the statistical testing, SPSS 21 was used to analyze the data through 8 one-way ANOVAs. The demographic characteristics were looked at separately in terms of their effect on acculturation and motivation. The realiability and validity of each scale was rechecked for the data entered. It was determined that for the acculutation scale for the participants with no children there was an internal consistency of $\alpha=.627$ (Cronbach's alpha) and for the acculturation scale for the participants with children there was an internal consistency of $\alpha=$.707. The motivation scale had an internal consistency of $\alpha=.803$. These are all acceptable alphas to ensure the reliability and validity of the scales. For the qualitative analysis, thematic analysis was used to analyze the qualitative data. Each answer for the qualitative questions was placed into themes. Within each theme direct quotes were used to show the personal thoughts and feelings concerning the questions. Both the quantitative and qualitative analysis provided an overall view of the results found in this study.

\section{Acculturation Level of Immigrant Parents}

To understand the impact of demographic factors on the level of acculturation, it is important to analyze the mean and standard deviation and understand what they respresent. Table 7 illustrates the mean, standard deviation, and sample size of each demographic factor on the immigrant parent's acculturation level. In the first demographic, number of children, the means are quite similar; however, those with zero children $(M=2.872)$ and one child $(M=2.819)$ show that they were slightly more 
acculturated than those with more children $(2, M=2.557 ; 3, M=2.567 ; 4, M=2.520 ; 5$, $M=2.583)$. For the factor of age, those with children 12 years or younger $(M=2.668)$ had a higher acculturation level than those with children who were older than 12 years $(M=2.542)$ and those who had children in both age ranges $(M=2.509)$. In terms of gender, those with only girls $(M=2.740)$ had slightly higher level of acculturation than those with boys $(M=2.564)$ and both, boys and girls $(M=2.531)$. Parents whose children were at the advanced English level $(M=2.621)$ were also slightly more acculturated than at the beginner $(M=2.579)$, intermediate $(M=2.541)$, or those with children at different levels $(M=2.479)$ Overall, looking at the means the acculturation level of the immigrant parents was relatively low (scale range 1 to 5) regardless of the demographic factor. The reason for such a low acculturation level mean may suggest an unconscious desire to maintain their native culture; however, this is explored further after analyzing the qualitative data. 
Table 7. Mean, Standard Deviation, and Sample Size of Demographics on Immigrant Parent's Acculturation

\begin{tabular}{|l|l|l|l|}
\hline Factor & M & SD & N \\
\hline Children & & & \\
0 & 2.872 & .594 & 19 \\
1 & 2.819 & .501 & 20 \\
2 & 2.557 & .551 & 60 \\
3 & 2.567 & .483 & 40 \\
4 & 2.520 & .728 & 26 \\
5 & 2.583 & .589 & 8 \\
\hline Age & & & \\
\hline 12 years or younger & 2.668 & .483 & 71 \\
Older than 12 years & 2.542 & .639 & 32 \\
Both & 2.509 & .614 & 51 \\
\hline Gender & & & \\
Boy & 2.564 & .573 & 37 \\
Girl & 2.740 & .444 & 37 \\
Both & 2.531 & .602 & 80 \\
\hline English Level & & & \\
Beginner & 2.579 & .457 & 18 \\
Intermediate & 2.541 & .565 & 33 \\
Advanced & 2.621 & .607 & 92 \\
Mixed Levels & 2.479 & .332 & 11 \\
\hline
\end{tabular}

\section{Motivation Toward Learning English}

Table 8 illustrates the mean, standard deviation, and sample size of demographics on the parent's motivation toward the English language. Looking at the means in all the sections of demographics, it is clear that the participants had a fairly high level of motivation toward the English language regardless of the demographic factor (scale range 1 to 4$)$. For the factor of children, the lowest mean was for four children $(M=3.683)$ and the highest mean was for three children $(M=3.778)$. For age, there was very little difference in the means of the three groups (12 years or younger, $M=3.792$; older than 12 
years, $M=3.730$; both, $M=3.691)$. With gender, the results showed that parents with girls $(\mathrm{M}=3.804)$ were slightly more motivated than those with boys $(M=3.652)$ or those with both $(M=3.762)$ For the English language level of children, there was very little difference between the means (Beginner, $M=3.833$; Intermediate, $M=3.718$; Advanced, $M=3.728$; Mixed, $M=3.830$ ). These results suggest that the majority of participants were highly motivated toward learning the English language.

Table 8. Mean, Standard Deviation, and Sample Size of Demographics on Immigrant Parent's Motivation to Learn the English Language

\begin{tabular}{|l|l|l|l|}
\hline Factor & M & SD & N \\
\hline Children & 3.694 & .367 & 19 \\
0 & 3.769 & .312 & 20 \\
1 & 3.741 & .378 & 60 \\
2 & 3.778 & .316 & 40 \\
3 & 3.683 & .450 & 26 \\
4 & 3.766 & .309 & 8 \\
5 & & & \\
\hline Age & 3.792 & .284 & 71 \\
\hline Oldear or younger & 3.730 & .413 & 32 \\
Both & 3.691 & .421 & 51 \\
\hline Gender & & & \\
Boy & 3.652 & .442 & 37 \\
Girl & 3.804 & .271 & 37 \\
Both & 3.762 & .355 & 80 \\
\hline English Level & & & \\
Beginner & 3.833 & .321 & 18 \\
Intermediate & 3.718 & .343 & 33 \\
Advanced & 3.728 & .391 & 92 \\
Mixed Level & 3.830 & .204 & 11 \\
\hline
\end{tabular}




\section{Statistical Analysis}

For research questions one and two, 8 one-way ANOVAs were used to determine the effect of the demographic factors on acculturation and motivation. This section discusses the results of the statistical analysis.

\section{How are children impacting the acculturation of the immigrant parent in the}

\section{United States?}

$\mathrm{Q}_{1}$ : Does the number of children have an effect on the immigrant parent's acculturation level?

$\mathrm{Q}_{2}$ : Does the age of children have an effect on the immigrant parent's acculturation level?

$\mathrm{Q}_{3}$ : Does the gender of children have an effect on the immigrant parent's acculturation level?

Q4: Does the English language level of children have an effect on the immigrant parent's acculturation level?

For research question one, sub-question one, a one-way ANOVA was used to evaluate the null hypothesis which stated that there is no significant effect of the number of children on the immigrant parent's acculturation level. The alpha was set at .05 to find the level of significance. The ANOVA for the effect of the number of children on the immigrant parent's acculturation level was not significant, $F(5,167)=1.621, p=.157$ (see Table 9). Due to these results of no significance, the null hypothesis failed to be rejected.

For research question one, sub-question two, a one-way ANOVA was used to evaluate the null hypothesis which stated that there is no significant effect of the age of children on the immigrant parent's acculturation level. The alpha was set at .05 to find the level of significance. The ANOVA for the effect of the age of children on the 
immigrant parent's acculturation level was not significant, $F(2,151)=1.324, p=.269$ (see Table 9). Due to these results of no significance, the null hypothesis failed to be rejected. For research question one, sub-question three, a one-way ANOVA was used to evaluate the null hypothesis which stated that there is no significant effect of the gender of children on the immigrant parent's acculturation level. The alpha was set at .05 to find the level of significance. The ANOVA for the effect of gender of children on the immigrant parent's acculturation level was not significant, $F(2,151)=1.809, p=.167$ (see Table 9). Due to the results of no significance, the null hypothesis failed to be rejected.

For research question one, sub-question four, a one-way ANOVA was conducted to evaluate the null hypothesis that stated there is no signficant effect of the English language level of children on the immigrant parent's acculturation level. The alpha was set at .05 to find the level of significance. The ANOVA for the effect of the English language level of children on the immigrant parent's acculturation level was not significant, $F(3,150)=.316, p=.814$. (see Table 9) Due to the results of no significance, the null hypothesis failed to be rejected.

Based on the results of the ANOVAs, the demographics factors related to participant's children are not having a significant impact on the acculturation level of the parent's. Looking at the means produced, it shows that those with fewer children ( 0 or 1) have a slightly higher level of acculturation. However, overall, all participants had a somewhat low score of acculturation level which signals some other underlying factor playing a role in the level of acculturation in these participants. 
Table 9. Impact of Demographics on Immigrant Parent's Acculturation

\begin{tabular}{|c|c|c|}
\hline Factor & $F$ & $P$ \\
\hline Children & 1.621 & .157 \\
\hline $\mathbf{0} \quad 1$ & & 1.000 \\
\hline 2 & & .291 \\
\hline 3 & & .391 \\
\hline 4 & & .371 \\
\hline 5 & & .834 \\
\hline 12 & & .479 \\
\hline 3 & & .588 \\
\hline 4 & & .487 \\
\hline 5 & & .920 \\
\hline 23 & & 1.000 \\
\hline 4 & & 1.000 \\
\hline 5 & & 1.000 \\
\hline 34 & & .999 \\
\hline 5 & & 1.000 \\
\hline 45 & & 1.000 \\
\hline Age & 1.324 & .269 \\
\hline \multirow{2}{*}{$\begin{array}{l}12 \text { years or younger- Older than } 12 \text { years } \\
12 \text { years or younger- Both }\end{array}$} & & .546 \\
\hline & & .276 \\
\hline Older than 12 years- Both & & .964 \\
\hline Gender & 1.809 & .167 \\
\hline Boy-Girl & & .371 \\
\hline Boy-Both & & .952 \\
\hline Girl-Both & & .149 \\
\hline English Level & .316 & .899 \\
\hline Beginner-Intermediate & & .996 \\
\hline Beginner-Advanced & & .992 \\
\hline Beginner-Mixed & & .967 \\
\hline Intermediate-Advanced & & 899 \\
\hline Intermediate-Mixed & & .989 \\
\hline Advanced-Mixed & & .861 \\
\hline
\end{tabular}




\section{How are children impacting the immigrant parent's motivation to learn the}

\section{English language in the United States?}

$\mathrm{Q}_{1}$ : Does the number of children have an effect on the immigrant parent's motivation to learn English?

$\mathrm{Q}_{2}$ : Does the age of children have an effect on the immigrant parent's motivation to learn English?

$\mathrm{Q}_{3}$ : Does the gender of children have an effect on the immigrant parent's motivation to learn English?

Q4: Does the English language level of children have an effect on the immigrant parent's motivation to learn English?

For research question two, sub-question one, a one-way ANOVA was conducted to evaluate the null hypothesis that stated that there is no signficant effect of the number of children on the immigrant parent's motivation to learn the English language. The alpha was set at .05 to find the level of significance. The ANOVA for the effect of the number of children on the immigrant parent's motivation to learn the English language was not significant, $F(5,167)=.308, p=.908$ (see Table 10). Due to the results of no signficiance, the null hypothesis failed to be rejected.

For research question two, sub-question two, a one-way ANOVA was used to evaluate the null hypothesis that stated that there is no significant effect of the age of children on the immigrant parent's motivation to learn the English language. The alpha was set at .05 to determine the level of significance. The ANOVA for the effect of the age of children on the immigrant parent's motivation to learn the English language was not significant, $F(2,151)=1.177, p=.311$ (see Table 10). Due to these results of no significance, the null hypothesis failed to be rejected. 
For research question two, sub-question three, a one-way ANOVA was used to evaluate the null hypothesis that stated that there is no significant effect of the gender of children on the immigrant parent's motivation to learn the English language. The alpha was set at .05 to determine the level of significance. The ANOVA for the effect of the gender of children on the immigrant parent's motivation to learn the English language was not significant, $F(2,151)=1.812, p=.167$ (see Table 10). Due to these results of no significance, the null hypothesis failed to be rejected.

For research question two, sub-question four, a one-way ANOVA was used to test the null hypothesis which stated that there is no significant effect of the English language level of children on the immigrant parent's motivation to learn the English language. The alpha was set at .05 to determine the level of significance. The ANOVA for the effect of the English language level of the children on the immigrant parent's motivation to learn the English language was not significant, $F(3,150)=.680, p=.565$ (see Table 10$)$. Due to these results of no significance, the null hypothesis failed to be rejected.

Based on these results, the demographic factors relating to children of immigrant parents are not having a significant impact on the motivation and attitude toward the English language. The means and standard deviations suggest that these participants have an overall high level of motivation toward the English language. The motivating factor of each of the participants may differ which will be explored and discussed in the qualitative analysis. 
Table 10. Impact of Demographics on Immigrant Parent's Motivation to Learn the English Language

\begin{tabular}{|c|c|c|c|}
\hline \multicolumn{2}{|c|}{ Factor } & $\mathbf{F}$ & $P$ \\
\hline \multicolumn{2}{|c|}{\begin{tabular}{rr}
\multicolumn{2}{r}{ Children } \\
\multicolumn{1}{r|}{ 0 } & 1 \\
& 2 \\
& 3 \\
& 4 \\
& 5
\end{tabular}} & \multirow[t]{5}{*}{.308} & $\begin{array}{c}.908 \\
.988 \\
.997 \\
.962 \\
1.000 \\
.997\end{array}$ \\
\hline 1 & $\begin{array}{l}2 \\
3 \\
4 \\
5\end{array}$ & & $\begin{array}{l}1.000 \\
1.000 \\
.969 \\
1.000\end{array}$ \\
\hline & $\begin{array}{l}3 \\
4 \\
5\end{array}$ & & $\begin{array}{l}.996 \\
.985 \\
1.000\end{array}$ \\
\hline & $\begin{array}{l}4 \\
5\end{array}$ & & $\begin{array}{l}.905 \\
1.000\end{array}$ \\
\hline \multicolumn{2}{|c|}{4} & & .993 \\
\hline \multicolumn{2}{|c|}{$\begin{array}{l}\text { Age } \\
12 \text { years or younger- Older than } 12 \text { years } \\
12 \text { years or younger- Both } \\
\text { Older than } 12 \text { years- Both }\end{array}$} & 1.177 & $\begin{array}{r}.311 \\
.704 \\
.289 \\
.883\end{array}$ \\
\hline \multicolumn{2}{|c|}{$\begin{array}{l}\text { Gender } \\
\text { Boy-Girl } \\
\text { Boy-Both } \\
\text { Girl-Both }\end{array}$} & 1.812 & $\begin{array}{r}.167 \\
.168 \\
.280 \\
.824\end{array}$ \\
\hline \multicolumn{2}{|c|}{$\begin{array}{l}\text { English Level } \\
\text { Beginner-Intermediate } \\
\text { Beginner-Advanced } \\
\text { Beginner-Mixed } \\
\text { Intermediate-Advanced } \\
\text { Intermediate-Mixed } \\
\text { Advanced-Mixed }\end{array}$} & .680 & $\begin{array}{c}.565 \\
.698 \\
.677 \\
1.000 \\
.999 \\
.813 \\
.819\end{array}$ \\
\hline
\end{tabular}




\section{Qualitative Analysis}

Research questions three and four were looked at qualitatively through three questions listed on the survey. Participants voluntarily answered these questions to give a personal reflection into their experiences and feelings about the English language in the United States and the impact that it may be having in their lives. These research questions include:

\section{What are the main motivating factors for learning the English language?}

\section{How have the children's English language learning affected the family unit in} the United States?

$\mathrm{Q}_{1}$ : How have the roles within the family been affected by the English language?

$\mathrm{Q}_{2}$ : How have the children's English language learning impacted the practice of the native language and culture within the family?

For the qualitative analysis the three areas of: 1) motivation, 2) roles within the family structure, and 3) impact on the native language and culture in terms of English language learning will be looked at separately to understand the experiences of the participants deeper. For each area, several themes emerged which gives a sense of their feelings and the impact on their family life. These themes are discussed and analyzed in this section.

\section{Motivation for Learning English}

When the participants were asked to list their main motivating factors for learning English, four major themes emerged: 1) children, 2) work/career, 3) community, and 4) to have self confidence and independence. Many of the participants listed factors that could be incorporated into more than one of these themes. For example, one participant stated, "primarily, to obtain a better job so I can give my children an education and also 
to cope better in this country." They viewed learning the English language was the key to acquiring a good job which would enable to them to send their children to good schools and have a better life in the United States. Another participant stated, "It is the first language that is spoken in this country, in my community, in work, and school, etc. and for my personal achievement. I would like to speak it and get a good job and communicate better with my children." While some participants had many factors motivating their English language learning such as those already discussed, many were very focused on the factors guiding their desire to learn English. Table 11 lists the frequencies of each theme.

Table 11. Motivating Factors for Learning English

\begin{tabular}{|c|l|}
\hline Motivating Factor & Number of Responses \\
\hline Children & 103 \\
Work/Career & 78 \\
Community & 50 \\
Self Confidence and Independence & 47 \\
\hline
\end{tabular}

\section{Children.}

Children was the motivating factor with the most responses. The participants expressed that it was very important for them to learn English in order for them to help their children in different aspects of their lives. One participant stated that what motivated them to learn English was, "to be involved together with my children and it frustrates me that I am not with everything and I need more so that I am not intimidated." This participant clearly showed the frustrations that many of the participants were feeling 
with not knowing the English language, particularly for the sake of their children. Another participant expressed that their motivation was, "to speak with teachers, to help more in the school, and to know what my children are saying." Many participants felt left out of the education process of their children because they did not know the language and felt a disconnect between themselves and their children in respect to their education. With the lack of the English language knowledge, these immigrant parents struggled to help their children with their homework and take an active part in the schools. Several participants mentioned that it was their main motivating factor to help their children understand and explain homework to help them succeed in school. They wanted to play an active role in their child's education, but felt restrained due to the language barrier. These participants talked about the desire to be involved in their children's learning process and the school environment. This illustrates the need to explore the issue of parental engagement of the immigrant parents within the public school system in the future. While taking a more prominent role in their child's education such as speaking with teachers, taking part in school meetings, and helping with homework was the main reason for children being a motivation factor, these parents also wanted to improve communication between themselves and their children by learning the English language. They had the desire to learn the English language to understand their children more, the relationships of these children, and their activities in this society.

\section{Work/Career.}

Work and career was a constant theme that proved to be important in the participants wanting to advance their English language learning. Such areas within the theme that were discussed included to be able to find a job and to advance to a better 
position which could increase their salary. One participant expressed their motivation was to, "get a better job for the well being of my family and get money for my children to go to university." Participants also listed such factors as: to be able to speak with coworkers, to understand the employer and job completely, and to keep from losing a job. This showed that they not only wanted English for the sake of obtaining a job, but to be able to perform that job well. One participant expressed that they wanted to learn English, "to be better in my job, to better communicate with other people at work." Learning English was also a concern for some in terms of mainting their job or position. They simply stated, "I have lost jobs."

\section{Community.}

Aspects of community were also suggested as a reason why these participants wanted to learn English and succeed in the language. One such area that was emphasized was to be able to socialize with their neighbors and other Americans. One participants stated that one motivating factor was to "be active participant in community and this country." Knowing the English language would allow them to form relationships to become a part of the community. Another stated that their motivation was "to be able to serve my community." This shows that they not only wanted to live within these communities, but to work to make it better and have a purpose in the community. Participants also identified being able to understand the doctors as an important motivating factor. One stated their motivating factor was to "communicate for my children's school, their health, better communication." This shows the practical reasons behind learning English. They wanted to be able tohave access and ease to necessities within their community, particularly for their children, such as visits to the doctors. 
Finally, within the theme of community, many participants saw that it was important to learn the English language in order to become integrated into society and to understand and accept the culture of the United States. One saw that by learning English, it would help to "communicate to integrate in the community, to help my children dominate the language of the place where we live."

\section{Self-Confidence and Independence.}

The final theme discovered of motivating factors for learning English was to create self-confidence and independence. Within this theme participants discussed the desire the reduce or eliminate the need for a translator in many different settings, for them to be confident in what is said to them and be able to answer for themselves, to not have to rely on others for daily needs and tasks, to receive citizenship, and to be able to defend themselves in this society. Many participants mentioned that they were still in need of translators, especially when it concerned their children. One participant stated they were motivated to learn English "to understand what my children are saying, meetings at the school and not to ask for a translator." By being to speak and understand for themselves they could increase their self confidence and self reliance. A factor that many participants felt strong importance within this theme was the ability to defend themselves and their children in this society. With a lack of the English language, it is difficult for them to stand up for their rights and demand what is deserving to them. One participant only wrote to defend themselves against "racism and discrimination" as their motive for learning the English language. Another went further to explain the situation, "I feel powerless when I go to the store and they treat me bad, I feel bad because I can't defend myself." 


\section{Roles Within the Family}

When participants were asked how the English language has impacted the roles within the family structure several themes emerged of which many were consistent with studies looked at in the literature review. Such issues that the participants discussed included: children acting as language brokers for their parents, miscommunication between parent and child, the parents having a feeling of helplessness within their family structure, and creating a positive relationship within the family. Each of these themes were analyzed to understand the experience that the family, in particular the parent, was going through due to the English language use in the United States. The participant responses signify what they see as changes and impacts on the traditional roles within the family. This section will look at each theme in more detail and illustrate through the participant's own words their feelings on the impact of English on the family structure.

\section{Children as Language Brokers.}

Children as language brokers was a theme in many of the responses on the survey. The participants expressed that their children often spoke for them in different settings whether that be at school, at the doctor, at the store, or within the community. "My children speak with their teachers and when we go to the doctor" stated one participant. While the children may choose to translate to make the process smother for both the parent and the other individual, other times it may be the only option for an exchange to occur between the parent and the other recipient. "My child has to speak for me." This suggests that the parent relies on the child for the communication outside of the home. This shows that the child takes on the role as the responsible individual in the relationship. Sometimes this responsibility may be too much for a child to handle and is 
frustrating for both the child and parent. One participant wrote, "sometimes children don't know how to translate for me." This could be caused by the children not understanding the translation process and the importance of it for their parent, or the English language may over dominate the child's vocabulary in comparison to the Spanish language. Some participants expressed that the translation process and relying on their child can be shameful. One stated, "it affects in the way that it embarrasses one to relate with other people, meetings, doctor, etc."

\section{Miscommunication between Parent and Child.}

The basic issue within miscommunication between parent and children is that the parents cannot understand their children. Many participants stated that when their children speak they do not understand. This can cause a feeling of disconnect and frustration between parent and child. One stated, "there are times that I can't communicate well with my children or feel that they don't understand me." Still, another problem is when both English and Spanish are being spoken in the home at the same time. A participant said we "speak both languages at the same time and is confusing." This can cause a great deal of miscommunication within the conversation between the parents and children. Another problem that participants have noticed within their family stems from the issue that the children know their parents do not understand the language. This has at many times brought about negative impacts on the family structure. One participant stated, "the children sometimes think they are better that they know and we don't understand everything." This has caused problems between the parent and child relationship and has brought on feelings of negativity on both parties. At times, it was shown that the children take advantage of this situation for their own benefit. One stated, 
"the children know one of their parents do not know the language and they lie about problems in the school." Trust and honesty become an issue that parents must deal with due to a lack of English knowledge. When there is more than one child at home, the children often speak English and the parent does not understand. "Children speak in English with each other and it is important to know what they are saying" wrote one participant. Another stated, "my children argue and discuss in English and sometimes I don't understand and that upsets me."

\section{Feelings of Helplessness.}

Some participants also expressed feelings of helplessness in relation to their family structure. They felt that they could not help their children or had to rely on others for help in their own daily tasks. One stated, "it's frustrating that I can't help my children when they need me." Another said, "I can't help my children with their homework." They felt that their ability play the important role of the parent in helping their children was taken away due to their lack of knowing the English language. Another participant felt a struggle of the parents trying to rely on one another for help. They stated, "my husband asks me to translate something that I don't understand." In this sense, the participant not only feels helpless with her children, but also her spouse, which can impact the relationship within the family in a negative way.

\section{Creating more Positive Relationships Within the Family.}

While these previous themes may have created negativity within the family structure, a small percentage of participants expressed a positive side of the increased use of the English language. One participant stated, "positive, my children are bilingual and so is my husband, and I am in the process." With family members using the English language, 
it has served as a motivation for other family members to acquire the language as well. Others did not see the use of English in the home. Perhaps it was strictly used as necessity within the community. For example, one stated that the roles within the family "hasn't been affected because we all speak Spanish." Still, others used the practice of English in the home to their advantage and were supported by their family to continue the use of Spanish. "My children support me and correct my English just as I correct their Spanish." The reasoning behind why some participants are experiencing positive relationships within the family and others are experiencing negativity is an area that needs further exploration in the future. Specific social factors may be playing a role, which would be beneficial to explore to understand why some immigrant families cite a positive experience and others experience negativity due to the English language. Impact of Children's English on the Practice of Spanish and Cultural Customs in US

From the participant's responses of the third qualitative question, it was revealed that the children's English is in fact having an effect on the practice of Spanish and the Hispanic cultural customs in the United States. The majority of participants expressed an increase use in the amount of English being used in the home and the American customs being practiced. The following quotes illustrates how the English language and American cultural customs are becoming a bigger part of the Hispanic family tradition in the United States:

"a few times I speak English with my children, but they always communicate in English with each other."

"yes, because they want to go to the other side and I cannot go with them or they don't want me."

"they teach me the language and how to understand the customs of the community." 
"kids know Spanish, but like to speak in English more. They enjoy watching movies in English, for example."

" 2 culture or 2 language always change the things in place."

“the children don't speak Spanish like they should; they don't know our Mexican customs."

"yes, it affects us because they take more to the customs of the US because they identify more in English than in Spanish

"My children like to speak in English and the customs, but are not interested in the Mexican culture very culture."

Other participants recognized that the English language and American cultural customs were beginning to replace the native language and culture:

"the children speak less Spanish and are more interested in things and culture of US. They give less importance to the Spanish culture."

"a lot because the children practice English at school, with their friends and teachers, and at home there is little time for Spanish."

"yes, they don't speak Spanish well and they don't practice our culture."

"English is easier for them than Spanish and they don't want to speak Spanish in the house."

"one of my daughters cannot speak some words in Spanish and cannot translate."

"my children don't speak much Spanish and they don't have much interest in my culture."

"the children don't speak Spanish and like the customs of US"

“our children don’t follow Mexican customs."

"Yes, the children already don't want to speak Spanish."

"yes, we have lost a lot of the customs, about all the language."

"yes, we have a lack of communication. Children are not interested in our culture." 
"Children don't want to speak Spanish and it is difficult to know what they are thinking."

Some saw their home and family turning into a bilingual and bicultural one:

"they can speak in two languages."

"we adopt the customs of both countries"

"no, both languages are used equally"

"yes, they are two different culture, but are dominating 2 languages"

"no, we try to balance both cultures."

"children speak both languages and communicate a lot in both languages"

"My children speak English and Spanish very well. They practice our culture and also their culture."

From these responses it is shown that the English language is affecting the Spanish language and culture in the home. In some cases, English is being used more and more. In other cases, English and the cultural customs of the United States are starting to over dominate the Spanish language and Hispanic culture. Still, others see that their home is becoming a bilingual and a bicultural one in which both languages and both cultures are accepted and practiced. However, overall, the practice of the native language and culture have been altered.

\section{Conclusion}

In this chapter, the results of the data analysis were discussed. By looking at the means and standard deviations it was shown that the majority of participants were not very acculturated to the American society; however, they had a very high level of motivation to learn the English language. The quantitative analysis showed that there was no real significance; however, this does not mean that the results are not important. 
The participants were able to express their experience and the impact of their children on their acculturation and English language learning experience much better through the qualitative data. Through this it was shown that children, are in fact, a strong motivating factor in learning English; however, the children's rate of acculturation and acquisition and use of the English language may influence the parents in resisting acculturation by trying to maintain the native language and culture for the sake of their family. Chapter 5 will look at these findings further by relating them to previous studies as well discuss the implications of such findings. 


\section{Chapter 5: Discussion and Conclusion}

\section{Summary}

With the increase in immigration in the United States, the need for studies which look at the growing immigrant population is great. It is important to understand the experiences of this population in the society in order to assess their needs and help them overcome the challenges they face so they can become contributing members to the new society. Two areas of concern with this population is the acquisition of the English language and acculturation. While much research has been done in terms of how bilingualism and biculturalism have impacted the children within these immigrant families, very few studies have focused on the parents and how the children's English language learning and acculturation have impacted their own English learning and acculturation. This study attempted to fill that lack of research by exploring the sociolinguistic impact that children are having on their immigrant parents. This research had three main goals: 1.) to determine the effect of children on the parent's acculturation level, 2.) to determine the effect of children on the parent's motivation to learn English, and 3) to explore the effect of the English language use on the family structure of these immigrant families. In order to approach these goals, four main research questions were used:

1. How are children impacting the acculturation of the immigrant parent in the United States?

$\mathrm{Q}_{1}$ : Does the number of children have an effect on the immigrant parent's acculturation level?

$\mathrm{Q}_{2}$ : Does the age of children have an effect on the immigrant parent's acculturation level? 
$\mathrm{Q}_{3}$ : Does the gender of children have an effect on the immigrant parent's acculturation level?

Q4: Does the English language level of children have an effect on the immigrant parent's acculturation level?

2. How are children impacting the immigrant parent's motivation to learn the English language in the United States?

$\mathrm{Q}_{1}$ : Does the number of children have an effect on the immigrant parent's motivation to learn English?

$\mathrm{Q}_{2}$ : Does the age of children have an effect on the immigrant parent's motivation to learn English?

$\mathrm{Q}_{3}$ : Does the gender of children have an effect on the immigrant parent's motivation to learn English?

Q4: Does the English language level of children have an effect on the immigrant parent's motivation to learn English?

3. What are the main motivating factors for learning the English language?

4. How have the children's English language learning affected the family unit in the United States?

$\mathrm{Q}_{1}$ : How have the roles within the family been affected by the English language?

$\mathrm{Q}_{2}$ : How have the children's English language learning impacted the practice of the native language and culture within the family?

These questions were evaluated using both quantiative and qualitative methods.

The data was collected using a survey that included an open-ended questionnaire.

Questions one and two used 8 one-way ANOVAs to determine the effect of children demographics on the immigrant parent's acculturation level and motivation/attitude toward the English language. Both descriptive statistics and inferential statistics were used to evaluate questions one and two. Questions three and four were evaluated using 
thematic analysis. For this study, it was found that the qualitative analysis provided a much clearer picture of the experience of the participants through the use of their own individualized words.

\section{Discussion of Findings}

This study found that while there were not any significant differences between the levels of the children demographic factors on the impact of acculturation level of parents and motivation and attitude toward the English language, it was determined that the participants in this study had an overall low acculturation level, but a significantly high level of motivation and attitude toward the English language. According to Krashen (1982), a relationship exists between acculturation and motivation. It is suggested that acculturation may motivate second language acquisition; however, by these results these participants have a very high level of motivation regardless of their demographic factors related to children and a low level of acculturation which does not support the notion that acculturation could be motivating these participants to learn English. However, these results do not exclude that acculturation motivates second language learning because the relationship between acculturation and motivation was not looked at exclusively. A high level of acculturation could, in fact, motivate learners in acquiring English; however, in this case, it did not play a role.

Looking closer at the results obtained from the impact of children on the immigrant parent's acculturation level, it is shown that those with fewer children ( 0 or 1$)$ have a slightly higher acculturation level $(M=2.872$ and $M=2.819)$ than those with more children $(2, M=2.557 ; 3, M=2.567 ; 4, M=2.520 ; 5, M=2.583)$. This suggests that participants with children may feel a need to retain their native culture for the sake of the 
children. They fear losing their native identity and traditions as the children become more acculturated into the American society. This is supported by many of the responses from the qualitative section of this study. One of the participants stated, "the children speak less Spanish and are more interested in things and culture of US. They give less importance to the Spanish culture." Another stated, "my children don't speak much Spanish and they don't have much interest in my culture." According to Silverstein and Chen (1999), Santisteban and Mitrani (2005), and Cortez (2008), acculturation gaps include the struggle to retain cultural values, beliefs, and relationship within the family. The parents' reflections on how the child's use of English has impacted the native language and culture suggests that they are frustrated with the child's disinterest in the native culture and may be trying to maintain the native culture in the home which has resulted in the parent refraining from being acculturated into the American society which is resulting in these acculturation gaps that is evident from these quotes.

Sabogal et al. (1987), Tseng and Fuligni (2000), and Smokowski et al. (2008) found that as acculturation increases, family cohesion begins to break down. Tseng and Fuligni (2000) also said that there is high cohesion with the native language. The participants in this study were also able to illustrate this through their thoughts. One participant stated, "the children sometimes think they are better that they know and we don't understand everything." Another wrote, “sometimes, my children don't communicate with me." These participants found that as the children became more acculturated and proficient with the English language, a disconnect was occurring between parent and child due to miscommunication. Many had problems just 
communicating and understanding their children while others saw their children behaving differently due to their parents lack of knowledge of the new society and new language.

Another discovery through the qualitative analysis that was supported by the review of literature was the change that these participants were seeing and feeling within their families. Many saw their children taking on the role of translator. One participant stated, "the children speak to their teachers and doctors for me." Many parents must rely on their children to understand and get by in this society. They become dependent on their child to provide the connection between them and the new culture and language. According to Tse (1995) and Dorner et al. (2008), children act as the language brokers at schools, doctors' offices, banks, and home, which is shown in this study. Many participants remarked how they had to have their children speak for them, translate for them, or explain the culture to them. Through this reliance on another, some participants discussed how they had a feeling of helplessness. One participant expressed, "it's frustrating that I can't help my children when they need me.” Santisteban and Mitrani (2003) found a feeling of loss of power of the parents through role reversal. Worthy (2006) and Weisskirch (2007) also found this negative impact on the parents involved in these situations in terms of resuming their traditional role as a parent that is meant to help their child rather than vice versa.

While many viewed the acculturation and English language impacting their family lives in a somewhat negative way, others welcomed the use of the English language and the American culture into the home and family. They believed that their family could be bilingual and bicultural and practice both languages and cultures. One participant stated that their experience was "positive, my children are bilingual and so is 
my husband, and I am in the process." While some may view practicing both cultures and languages challenging, some participants remarked that they are practicing both languages and cultures equally. This is supported by Teske and Nelson (1974) and Ryder, Alden, and Paulhus (2000) which stated that one can maintain two co-existing cultural identities. While there were some participants that viewed practicing a bicultural and bilingual lifestyle as beneficial for their families, it was a small minority in this study which suggests that it is often difficult to accomplish without having some negative effects.

When looking at the impact of children on the parent's motivation and attitude toward the English language, it was shown that the demographic characteristics of children do not have a significant impact; however, it was discovered that with all participants there was an overall high motivation and attitude toward the English language. While statistically, it cannot be confirmed that this is directly related to the children due to the fact the mean score for those with children $(1, M=3.769 ; 2, M=3.741$; $3, M=3.778 ; 4, M=3.683 ; 5, M=3.766)$ and those without children $(M=3.694)$ are very close in range, it is possible to suggest that those with children are motivated and have a positive attitude toward the English language because of their children regardless of the specific demographic characteristics, as well as those without children are motivated by some other factor which was explored more in the qualitative data. To understand the factor that may be impacting the motivation and attitude toward the English language, it is necessary to consider the qualitative data to get a clearer picture of these results.

Through the qualitative data, it was shown that family was a common theme described in most of the responses. This coincides with the issue of familism that was 
discussed in the literature review. According to Sabogal et al. (1987), Cuellar et al. (1995), Bacallao and Smokowski (2007), and Smokowski et al. (2008), familism is deeply rooted in Hispanic dynamics. The importance of family was shown through the responses concerning the motivating factors for learning English. This is also supported by Gardner (1968) which found that the family impacted one's motivation in learning a second language. Four themes were found in the responses concerning motivating factors for learning the English language. These included: children, work/career, community, and self-confidence and independence.

The participants in this study expressed a desire to learn English for their children. They wanted to resume the role of parent by being able to help their children. This included helping their children with school, with daily necessary tasks, relieving their children of added responsibility of acting as the translator for the family, and for better communication with their children. One participant stated that their motivating factor was "to speak with teachers, to help more in school, and to know what my children are saying." This shows that their children are their main motivation in acquiring the English language. In addition to children, work and career was a common response in explaining the participant's motivating factor. While many of these participants expressed that they would like to obtain a better job or increase their salary as the reason behind wanting to learn English, they also had the intention of doing this for their children. One participant stated that their motivation for learning English was "primarily, to obtain a better job so I can give my children an education and also to cope better in this country." Another stated, "to get a better job for the well being of my family and get money for my children to go to university." All of these responses support the notion 
that parents want and find it necessary to learn English for their children to advance in this new society.

Within the themes of community and self-confidence and independence, underlying themes pertaining to children were also found. The participants expressed that they wanted to learn English in order to be active and take part in the community. One participant stated that their motivation was to "communicate to integrate in the community, to help my children dominate the language of the place where we live." The community theme also showed the desire for participants to be able to participate in their children's schools and communicate with their doctors. The issues addressed in the selfconfidence and independence theme illustrated a better picture of these participant's experience and feelings in the American society, both for themselves and their children. The basic reason within this theme was to be more self reliant and confident in situations involving English whether that be at schools, hospitals, stores, or social gatherings. They wanted to be able to eliminate the need for translators. However, the participants that talked about defending their rights really showed the difficulty and frustration that some are experiencing. One participant wrote, "I want to communicate easier with all types of people and whatever situation, I want to be able to defend myself and defend my children."

From the analysis focusing on parent's motivation and attitude toward the English language, it is evident that children are a main factor for motivation. While in this study motivation was looked at as a whole, Gardner and Lambert (1959) described two orientations of motivation: integrative and instrumental. Integrative motivation is "where the aim in language study is to learn more about the language group, or to meet more and 
different people", whereas, instrumental is "where the reasons reflect the more utilitarian value of linguistic achievement" (Gardner \& Lambert 1959, p. 267). In this study, the participants possess both orientations, although, their motivation may seem to be more instrumental due to the reasoning behind why they want to learn English. The majority of participants mentioned that they wanted to learn English for a practical purpose either to be able to speak with their children's schools, to help with homework, or to obtain a better job; however, these are also integrative in nature due to the fact that they are surrounded by the culture and the people who speak the language in order for them to achieve these goals and many of the participants wanted to become part of the community. According to Gardner (1985) this is part of instrumental motivation because instrumental motivation involves interaction with the host community, which was shown in this study.

\section{Recommendations for Greater Community Outreach}

The findings from this study suggest that there is a need for greater community outreach for immigrant families, even in diverse locations such as the one in which this took place. It was shown in this study that the participants in this study have a very high motivation to learn the English language; however, their acculturation rate is somewhat low. The majority of participants recognized their children as a driving force in their motivation to learn English in order to communicate better with the schools, help them with their homework, communicate better with them, and resume their traditional parental roles. Based on these findings, the researcher has developed five recommendations to improve English language learning as well as increase acculturation based on the social context of these participants. These recommendations include: 
1) The public school system should explore ways in which to better address the needs of the immigrant parents. It is suggested that school districts with a high population of biculturalism and bilingualism offer ESL and culture programs at the schools for these immigrant parents. These programs should focus on understanding the school system as well as basic English that will focus on the skills needed to help their children with their schoolwork. Appendix E provides a list of best practices and language models for Hispanic immigrant parents that address the needs of the parents and improves parental engagement with the school system.

2) The schools should also reach out to the immigrant parents by holding special multicultural days to increase their involvement in their child's education. This would give them a chance to not only be actively involved in the school, but also to be proud about their culture and give their knowledge while using the English they do know. This would also allow them to become more comfortable and familiar with the American school culture.

3) Teacher education programs should prepare their students in working with immigrant parents. They should develop skills to initiate involvement from parents with limited English ability and cultural knowledge.

4) ESL educators in community/nonprofit programs should understand that their students have diverse needs in terms of their English language learning. They can customize their teaching to fit the needs of the students. For example, it may be beneficial to hold separate classes based on the specific needs. 
5) It would be beneficial for the community to offer parent/child ESL and culture classes as a way to learn the language and culture as well as promote family cohesion and communication. These classes should involve both the parent and child participating and working together to improve their English language skills and cultural knowledge.

\section{Conclusion and Future Research}

Through this study a more thorough understanding of the parent's acculturation and English language learning in a new society was shown. It was found that these participants have an overall low acculturation rate and a high motivation and attitude toward the English language regardless of the children demographic factors through the statistical testing. However, the qualitative data allowed the researcher to generate a more vivid picture of these participants' experiences with the new language and culture. It was found that the children's English language acquisition and acculturation were, in fact, having an impact on the parents and the family as a whole. This study was meant to break into a new research area that focused on the experience of the immigrant parent. It is important to understand this population and their needs in terms of acculturation and English language learning to help them evolve into active contributing members to society. By focusing on the parents and their needs, the next generation will be better prepared for success because the children will benefit from the knowledge and advancement of their parents.

While this study had informative and beneficial findings, future research would allow for even greater understanding. The acculturation scale and the motivation/attitude scale were short and concise, future research should expand these scales to possibly get a 
better measurement of acculturation and motivation and attitude. With the motivation scale, a future study could focus on distinct measurements of the two orientations, integrative and instrumental. This would allow for a better understanding of the basis of their motivation.

There are many issues pertaining to this particular population that were not addressed in this study. This was due to the sensitivity of these issues and the methods in which data was collected. Some of these issues include the legal status of these participants as well as their literacy. These factors may play a role in the experience of the immigrant parent and family. Future research could explore issues such as these and how they may impact the immigrant parent and family experience; however, it would be best for sensitive issues such as these to be explored qualitatively in order to instill trust in the participant.

It would be beneficial for future research pertaining to the topic to use more qualitative methods. This could include focus group interviews, one-on-one interviews, as well as reflective writing. Rich data could be obtained from these methods that would allow for the researcher to conduct follow-up questions to the responses. It would provide a more in depth view of the participant's experience as well as the freedom to explore topics that the participant chose to talk about. In addition, it would also be beneficial to allow the children of these parents to take part in the study to get a complete picture of the family dynamics and how they have been impacted by the English language.

A final suggestion for future research would be to expand this study to include other cultural groups within the United States. This study was strictly focused on 
Hispanic immigrant parents; however, in the United States there are many cultural groups to apply this study. It would be informative to see any differences that exist between the cultural groups to gain a better understanding of these parents and how to address their specific needs in terms of acculturation and English language learning in order to benefit their children, their community, and themselves. 


\section{References}

Acoach, C., \& Webb, L. (2004). The Influence of Language Brokering on Hispanic Teenagers' Acculturation, Academic Performance, and Nonverbal Decoding Skills: A preliminary study. The Howard Journal of Communications, 15, 1-19.

Bacallao, M., \& Smokowski, P. (2007). The Costs of Getting Ahead: Mexican family system changes after immigration. Family Relations, 56, 52-66.

Berry, J. (1997). Immigration, Acculturation, and Adaptation. Applied Psychology: An International Review, 46(1), , 5-68.

Cortez, M. (2008). Trying to Fit in a Different World: Acculturation of Latino families with young children in the United States. International Journal of Early Childhood, 40(1),, 97-100.

Csizer, K., \& Dornyei, Z. (2005a). The Internal Structure of Language Learning Motivation and Its Relationship with Language Choice and Learning Effort. The Modern Language Journal, 89(i), 19-36.

Csizer, K., \& Dornyei, Z. (2005b). Language Learners' Motivational Profiles and their Motivated Learning Behavior. Language Learning, 55(4), 613-659.

Csizer, K, \& Kormos, J. (2008). The Relationship of Intercultural Contact and Language Learning Motivation among Hungarian Students of English and German. Journal of Multilingual and Multicultural Development, 29(1), 30-48.

Cuellar, I., Arnold, B., \& Gonzalez, G. (1995). Cognitive Referents of Acculturation: Assessment of Cultural Constructs in Mexican Americans. Journal of Community Psychology, 23, , 339-356.

Cuellar, I., Arnold, B., \& Maldonaldo, R. (1995). Acculturation Rating Scale for Mexican-Americans-II: A revision of the original ARSMA scale. Hispanic Journal of Behavioral Sciences, 17(3), 275-304.

Culhane, S. (2003). Sojourner Acculturation Attitudes: Suggestions for learner motivation in second language acquisition (SLA). Bulletin of the Faculty of Education, Kagoshima University, Studies in Education, 59-73.

Culhane, S. (2004). An Intercultural Interaction Model: Acculturation attitudes in second language acquisition. Electronic Journal of Foreign Language Teaching, 1(1), 50-61.

Denver Public Schools. (2012). Facts and Figures. Retrieved October 10, 2013, from communications.dpsk12.org/facts.html 
Dorner, L., Orellana, M., \& Jimenez, R. (2008). "It's One of Those Things That You Do to Help the Family" Language Brokering and the Development of Immigrant Adolescents. Journal of Adolescent Research, 23(5),, 515-543.

Dorner, L., Orellana, M., \& Li-Grining, C. (2007). "I Helped My Mom," and It Helped Me: Translating the skills of language brokers into improved standardized test scores. American Journal of Education, 113(3), , 451-478.

Dornyei, Z., \& Csizer, K. (1998). Ten Commandments for Motivating Language Learners: Results of an empirical study. Language Teaching Research, 2(3), 203229.

Dornyei, Z. (2005). The Psychology of the Language Learner: Individual Differences in Second Language. Mahwah, NJ: Lawrence Erlbaum.

Dornyei, Z. (2009a). The L2 Motivational Self System. In Z. Dornyei and E. Ushioda (Eds.), Motivation, Language Identity and the L2 Self. Clevedon: Multilingual Matters.

Dornyei, Z. (2009b). Motivation and the Vision of Knowing a Second Language. In B. Beaven (Ed.), IATEFL 2008: Exeter conference selections (pp. 16-22). Canterbury: IATEFL.

Dornyei, Z. (2010). Researching Motivation: From integrativeness to the ideal self. In S. Hunston \& D. Oakey (Eds.), Introducing Applied Linguistics: Concepts and skills (pp.74-83). London: Routledge.

Duran, P. (2003). Children as Mediators for the Second Language Learning of their Migrant Parents. Language and Education, 17(5), 311-331.

Ely, C. (1986). Language Learning Motivation: A descriptive and causal analysis. The Modern Language Journal, 70(1), 28-35.

Engin, A. (2009). Second Language Learning Success and Motivation. Social Behavior and Personality, 37(8), 1035-1042.

Gardner, R., \& Lambert, W. (1959). Motivational Variables in Second-Language Acquisition. Canadian Journal of Psychology, 13(4), 266-272.

Gardner, R. (1968). Attitudes and Motivation: Their role in second-language acquisition. TESOL Quarterly, 2(3), 141-150.

Gardner, R. (1985). Social Psychology and Second Language Learning: The role of attitudes and motivation. London: Edward Arnold. 
Gardner, R. (1999). Correlation, Causation, Motivation, and Second Language Acquisition. Canadian Psychology, 41(1), 10-24.

Gardner, R., Masgoret, A., Tennant, J., \& Mihic, L. (2004). Integrative Motivation: Changes during a year-long intermediate-level language course. Language Learning, 54(1), 1-34.

Gordon, D. (1996). ESL and Parental Empowerment. Working Papers in Educational Linguistics, 12(1), 75-93.

Grieco, E.M., Acosta, Y.D., Patricia de la Cruz, G., Gambino, C., Gryn, T.,Larsen, L.J., et al. (2012). The Foreign-Born Population in the United States: 2010. U.S. Census Bureau, American Community Survey Reports, May 2012.

Huang, S. (2008). Assessing Motivation and Learning Strategies using the Motivated Strategies for Learning Questionnaire in a Foreign Language Context. Social Behavior and Personality, 36(4), 529-534.

Keefe, S. (1979). Urbanization, Acculturation, and Extended Family Ties: Mexican Americans in cities. American Ethnologist, 6(2), 349-365.

Kim, C., \& Miura, I. (1999). A Study of the Relationships between Acculturation, Cultural Identity, Family Bonding, and Parent-Child Conflict among the KoreanAmerican Adolescents. The Annual Meeting of the American Educational Research Associations, (pp.1-4). Montreal.

Kissau, S. (2006). Gender Differences in Second Language Motivation: An investigation of micro- and macro-level influences. Canadian Journal of Applied Linguistics, 9(1), 73-96.

Kormos, J., \& Csizer, K. (2008). Age-Related Differences in the Motivation of Learning English as a Foreign Language: Attitudes, selves, and motivated learning behavior. Language Learning, 58(2), 327-355.

Krashen, S. (1982). Principles and Practice in Second Language Acquisition. Oxford: Pergamon Press.

Lansford, J., Deater-Deckard, K., \& Bornstein, M. (2007). Immigrant Families in Contemporary Society. New York: Guilford Press.

Marin, G., Sabogal, F., Marin, B., Otero-Sabogal, R., \& Perez-Stable, E. (1987). Development of a Short Acculturation Scale for Hispanics. Hispanic Journal of Behavioral Sciences, 9(2), 183-205. 
Martinez, J. C., McClure, H., \& Eddy, J. (2009). Language Brokering Contexts and Behavioral and Emotional Adjustment Among Latino Parents and Adolescents. Journal of Early Adolescence, 29(1), 71-98.

Masgoret, A., \& Gardner, R. (2003). Attitudes, Motivation, and Second Language Learning: A meta-analysis of studies conducted by Gardner and Associates. In Dornyei, Z. (Ed.), Attitudes, Orientations and Motivations in Language Learning (pp.167-210). Oxford: Blackwell.

Massey, D.S. (1995). The New Immigration and Ethnicity in the United States. Population and Development Review, 21(3), 631-652.

Mead, M. (1970). Culture and Commitment: A study of the generation gap. Garden City, NJ: Natural History Press.

Noels, K., Pelletier, L., Clement, R., \& Vallerand, R. (2000). Why Are You Learning a Second Language? Motivational orientations and self-determination theory. Language Learning, 53, 33-64.

Oxford, R., \& Shearin, J. (1994). Language Learning Motivation: Expanding the theoretical framework. The Modern Language Journal, 78(1), 12-28.

Pew Research Center. (2011). Hispanic Population in Select U.S. Metropolitan Areas, 2011. Retrieved October 10, 2013 from www.pewhispanic.org/2013/08/29/hispanic-population-in-select-u-smetropolitan-areas-2011/

Quinones-Mayo, Y., \& Dempsey, P. (2005). Finding the Bicultural Balance: Immigrant Latino mothers raising "American" adolescents. Child Welfare, LXXXI, 5, 649667.

Rubenfeld, S., Sinclair, L., \& Clement, R. (2007). Second Language Learning and Acculturation: The role of motivation and goal content congruence. Canadian Journal of Applied Linguistics, 10(3), 309-323.

Rueschenberg, E., \& Buriel, R. (1989). Mexican American Family Functioning and Acculturation: A family systems perspective. Hispanic Journal of Behavioral Sciences, 11, 232-244.

Ryder, A., Alden, L., \& \& Paulhus, D. (2000). Is Acculturation Unidimensional or Bidimensional? A head-to-head comparison in the prediction of personality, selfidentity, and adjustment. Journal of Personality and Social Psychology, 79(1),, 49-65. 
Sabogal, F., Marin, G., Otero-Sabogal, R., Marin, B., \& Perez-Stable, E. (1987). Hispanic Familism and Acculturation: What changes and what doesn't? Hispanic Journal of Behavioral Sciences,9, 397-412.

Santisteban, D., \& Mitrani, V. (2003). The Influence of Acculturation Processes on the Family. In K. Chun, P. Organista, \& G. Marin, Acculturation Advances in Theory, Measurement, and Applied Research. Washington, D.C.: American Psychological Association.

Schofield, T., Parke, R., Kim, Y., \& Coltrane, S. (2008). Bridging the Acculturation Gap: Parent-child relationship quality as a moderator in Mexican American families. Developmental Psychology, 44(4), 1190-1194.

Schumann, J. (1978). The Acculturation Model for Second-Language Acquisition. In R.C. Gingras, (Ed.), Second Language Acquisition and Foreign Language Teaching. Washington, D.C.: Center for Applied Linguistics.

Schumann, J. (1986). Research on the Acculturation Model for Second Language Acquisition. Journal of Multilingual and Multicultural Development, 7(5), 379392.

Shoaib, A., \& Dornyei, Z. (2004). Affect in Life-Long Learning: Exploring L2 motivation as a dynamic process. In P. Benson \& D. Nunan (Eds.), Learners' stories: Difference and diversity in language learning (pp. 22-41). Cambridge: Cambridge University Press.

Silverstein, M., \& Chen, X. (1999). The Impact of Acculturation in Mexican American Families on the Quality of Adult Grandchild-Grandparent Relationships. Journal of Marriage and the Family, 61,188-198.

Smokowski, P., Rose, R., \& Bacallao, M. (2008). Accculturation and Latino Family Processes: How cultural involvement, biculturalism, and accuturation gaps influence family dynamics. Family Relations, 57, 295-308.

Souto-Manning, M. (2007). Immigrant Families and Children (Re)develop Identities in a New Context. Early Childhood Education Journal, 34(6), 399-406.

Spolsky, B. (1969). Attitudinal Aspects of Second Language Learning. Psychology of Second Language Learning Section of the Second International Congress of Applied Linguistics, (pp.8-12), Cambridge.

Teske, R. \&. (1974). Acculturation and Assimilation: A clarification. American Ethnologist, 1(2),, 351-367. 
Tremblay, P., \& Gardner, R. (1995). Expanding the Motivation Construct in Language Learning. The Modern Language Journal, 79(4), 505-518.

Trimble, J. (2003). Introduction: Social change and acculturation. In K. Chun, P. Balls Organista, \& G. \& Marin, Acculturation: Advances in theory, management, and applied research (pp. 3-13). Washington, D.C.: American Psychological Association.

Tse, L. (1995). When Students Translate for Parents: Effects of language brokering. CABE Newsletter, 17(4), 16-17.

Tse, L. (1996). Language Brokering in Linguistic Minority Communities: The case of Chinese- and Vietnamese-American Students . The Bilingual Research Journa, 20(3\&4), 485-498.

Tseng, V., \& Fuligni, A. (2000). Parent-Adolescent Language Use and Relationships Among Immigrant Families with East Asian, Filipino, and Latin American Backgrounds. Journal of Marriage and the Family, 62, 465-476.

Ushioda, E. (2010). Motivation and SLA: Bridging the Gap. EUROSLA Yearbook, 10, 520.

Vega, W., Patterson, T., Sallis, J., Nader, P., Atkins, C., \& Abramson, I. (1986). Cohesion and Adaptability in Mexican-American and Anglo Families. Journal of Marriage and Family, 48(4), 857-867.

Villanueva, C., \& Buriel, R. (2010). Speaking on Behalf of Others: A qualitative study of the perceptions and feelings of adolescent Latina language brokers. Journal of Social Issues, 66(1), 197-210.

Weisskirch, R. (2006). Emotional Aspects of Language Brokering among Mexican American Adults. Journal of Multilingual and Multicultural Development, 27(4), 332-343.

Weisskirch, R. (2007). Feelings About Language Brokering and Family Relations Among Mexican American Early Adolescents. Journal of Early Adolescence, 27(4), 545-561.

Worthy, J. (2006). Como Si Le Falta Un Brazo: Latino immigrant parents and the costs of not knowing English. Journal of Latinos and Education, 5(2), 139-154. 
Appendix A: Cover Letter (English)

Dear Participant,

My name is Melissa McIntosh and I am a doctoral candidate in the College of Human Resources and Education at West Virginia University. I am conducting a research study under the supervision of Patricia Obenauf, Ed.D., a professor in the College of Human Resources and Education at West Virginia University for my dissertation. The purpose of this study is to determine the impact of children on the parent's English language learning in the United States.

Attached is a short survey which asks questions about you and your experience with the English language. I am asking your help in completing this survey. The results of this study hope to create new ways of improving community outreach and parent engagement.

The survey will take approximately 5 to 10 minutes to complete. You must be 18 years of age or older to complete this survey. Your participation is completely voluntary and the responses will be kept confidential. You may skip any question that you do not wish to answer and you may discontinue at any time. If you choose to do so, please complete the survey and return it. The West Virginia Institutional Review Board (IRB) acknowledgment of this study is on file.

Sincerely,

Melissa McIntosh

Ed.D. Candidate

Curriculum \& Instruction

West Virginia University

540-449-9324

mmcinto1@mix.wvu.edu 
Appendix B: Cover Letter (Spanish)

Estimado Participante,

Me llamo Melissa McIntosh y soy una candidata de doctorada en el Colegio de Recursos Humanos y Educación en la Universidad de West Virginia. Yo estoy llevando a cabo un estudio de investigación bajo la supervisión de Patricia Obenauf, Ed.D., una profesora en el Colegio de Recursos Humanos y Educación en la Universidad de West Virginia para mi disertación. El propósito de este estudio es para determinar el impacto de los hijos en el aprendizaje del idioma inglés de sus padres en los Estado Unidos.

Se adjunta una breve encuesta que hace preguntas acerca de usted y su experiencia con el idioma inglés. Estoy pidiendo su ayuda para completar esta encuesta. Los resultados de este estudio esperan a crear nuevas formas de mejorar alcance a la comunidad y la participación de los padres.

Esta encuesta tomará aproximadamente 5 a 10 minutos para completarse. Debe tener 18 años o más para completar esta encuesta. Su participación es completamente voluntaria y sus respuestas serán confidenciales. Usted puede saltarse cualquier pregunta que no desee contestar y puede interrumpir en cualquier momento. Si decide hacerlo, por favor complete la encuesta y lo devuelve. El reconocimiento del Concejo de Revisión Institucional (IRB) de la Universidad de West Virginia para este estudio está en el archivo.

Atentamente,

Melissa McIntosh

Candidata de Ed.D.

Currículo y la Instrucción

La Universidad de West Virginia

540-449-9324

mmcinto1@mix.wvu.edu 
Appendix C: Survey (English)

Demographics: Please mark the most appropriate response.

1. City and Country of Origin:

2. Gender

( ) Male

( ) Female

3. Age
( ) 25 or younger
( ) 26-35
( ) $36-45$
( ) $46-50$
( ) 51 or older

4. Highest Level of Education Completed

( ) no schooling

( ) less than elementary

( ) elementary school

( ) middle school

( ) high school

( ) some college

( ) Bachelor's Degree

( ) Graduate Degree

5. Years in the United States

( ) less than 1 year

( ) 1 to 5 years

( ) 5 to 10 years

( ) more than 10 years

6. Annual Household Income

( ) less than $\$ 10,000$

( ) $\$ 10,000-\$ 19,999$

( ) $\$ 20,000-\$ 29,999$

( ) $\$ 30,000-\$ 39,999$

( ) $\$ 40,000-\$ 49,999$

( ) $\$ 50,000$ or more
7. Members in your Household

(Choose all that apply)

( ) spouse

( ) children

( ) extended family members

(parents, siblings, nieces, nephews, etc.)

( ) non-family members

8. Level of English
( ) none
( ) Beginner
( ) Intermediate
( ) Advanced

9. Are you currently studying English?
( ) yes
( ) no

10. Number of Children
( ) 0
( ) 1
( ) 2
( ) 3
( ) 4
( ) 5
( ) more than 5

11. Age of Children
( ) 12 or younger
( ) Older than 12
( ) Both

12. Gender of Children
( ) Male
( ) Female
( ) Both

13. English Level of Children
( ) Beginner
( ) Intermediate
( ) Advanced 
Acculturation: Using the number descriptions below, please circle the number that best describes you for each statement.
(1) Never
(2) Very Little
(3) Sometimes
(4) Frequently
(5) Almost all the time

1. I speak Spanish in my community.

(1) (2) (3) (4) (5)

2. I speak English in my community.

(1) (2) (3) (4) (5)

3. I speak Spanish with my children.

(1) (2) (3) (4) (5)

4. I speak English with my children.

(1) (2) (3) (4) (5)

5. I speak Spanish at work.

(1) (2) (3) (4) (5)

6. I speak English at work.

7. My children translate for me.

8. I communicate with my children's school.

(1) (2) (3) (4) (5)

(1) (2) (3) (4) (5)

9. In the US, I associate with Spanish-speakers.

(1) (2) (3) (4) (5)

10. In the US, I associate with English-speakers.

(1) (2) (3) (4) (5)

11. I practice cultural customs of my country.

(1) (2) (3) (4) (5)

12. I practice cultural customs of the United States.

(1) (2) (3) (4) (5)

(1) (2) (3) (4) (5)

Motivation/Attitude toward the English language: Please mark the response that best represents your attitude or motivation.

1. My motivation to learn English in order to communicate with English speaking people is:

( ) low ( ) somewhat low ( ) somewhat high ( ) high

2. My attitude toward English speaking people is:

$($ ) negative ( ) somewhat negative ( ) somewhat positive ( ) positive

3. My interest in English is:

( ) low ( ) somewhat low ( ) somewhat high ( ) high

4. My desire to learn English is:

( ) low ( ) somewhat low ( ) somewhat high ( ) high

5. My attitude toward learning English is:

( ) negative ( ) somewhat negative ( ) somewhat positive ( ) positive

6. My motivation to learn English for practical purposes (i.e. work) is :

( ) low ( ) somewhat low ( ) somewhat high ( ) high

7. My motivation to learn English for personal reasons (i.e. children) is:

( ) low ( ) somewhat low ( ) somewhat high ( ) high

8. My attitude toward attending an English class is:

$($ ) negative ( ) somewhat negative ( ) somewhat positive ( ) positive 


\section{Please answer the following questions.}

1. What are your greatest motivating factors for learning English?

2. How have roles within the family been affected by the English language?

3. Has your child's English language learning impacted your family's practice of Spanish and cultural customs in the United States? If yes, how?

Thank you for taking the time to complete this survey. 
Appendix D: Survey (Spanish)

Demografía: Por favor marque la respuesta más apropriada.

1. La Ciudad y El País de Origen:

2. El Sexo

( ) el hombre

( ) la mujer

3. La Edad

( ) 25 o menos

( ) 26-35

( ) $36-45$

( ) $46-50$

( ) 51 o más

4. El Nivel Más Alto de Educación

Alcanzado

( ) ninguna

( ) menos de la escuela primaria

( ) la escuela primaria

( ) la escuela media

( ) la escuela secundaria

( ) alguna universidad

( ) la universidad

( ) la escuela posgradua

5. Años en los E.E.U.U.

( ) menos de 1año

( ) 1 to 5 años

( ) 5 to 10 años

( ) más de 10 años

6. Ingresos Anual de la Familia

( ) menos de $\$ 10,000$

( ) $\$ 10,000-\$ 19,999$

( ) $\$ 20,000-\$ 29,999$

( ) $\$ 30,000-\$ 39,999$

( ) $\$ 40,000-\$ 49,999$

( ) $\$ 50,000$ o más
7. Miembros en su Casa en los E.E.U.U. (escoge todas las que correspondan)

( ) el/la esposo/a

( ) los hijos

( ) los miembros de la familia ampliada(los padres, los hermanos, los sobrinos)

( ) la gente que no son miembros de la familia

8. El Nivel del Inglés

( ) ningún

( ) principiante

( ) intermedio

( ) avanzado

9. ¿Está estudiando ingles corriente?

( ) sí

( ) no

10. El Número de los Hijos
( ) 0
( ) 1
( ) 2
( ) 3
( ) 4
( ) 5
( ) más de 5

11. La Edad de los Hijos
( ) 12 o menos
( ) más de 12
( ) los dos

12. El Sexo de los Hijos
( ) el niño
( ) la niña
( ) los dos

13. El Nivel del Inglés de los Hijos
( ) principiante
( ) intermedio
( ) avanzado 
Acculturación: Utilizando las descripciones númericas abajo, por favor haga círculo el número que le describe mejor para cada declaración.
(1) Nada
(2) Un Poquito
(3) A Veces
(4) Frequentemente
(5) Casi todo el tiempo

1. Yo hablo español en mi comunidad.

(1) (2) (3) (4) (5)

2. Yo hablo ingles en mi comunidad.

(1) (2) (3) (4) (5)

3. Yo hablo español con mis hijos.

(1) (2) (3) (4) (5)

4. Yo hablo inglés con mis hijos.

(1) (2) (3) (4) (5)

5. Yo hablo español al trabajo.

(1) (2) (3) (4) (5)

6. Yo hablo ingles al trabajo.

(1) (2) (3) (4) (5)

7. Mis hijos traduzcan para mí.

(1) (2) (3) (4) (5)

8. Me comunico con la escuela de mis hijos.

(1) (2) (3) (4) (5)

9. En los EE.UU., me asocio con la gente que hablan español.

(1) (2) (3) (4) (5)

10. En los EE.UU., me asocio con la gente que hablan ingles.

(1) (2) (3) (4) (5)

11. Yo practico los costumbres culturales de mi país.

(1) (2) (3) (4) (5)

12. Yo practico los costumbres culturales de los EE.UU.

(1) (2) (3) (4) (5)

Motivación/Actitud hacia el idioma ingles: Por favor marquee la respuesta que representa su actitud o motivación el mejor.

1. Mi motivación para aprender inglés para comunicarse con la gente que hablan inglés es:

$$
\text { ( ) bajo ( ) algo bajo ( ) algo alto ( ) alto }
$$

2. Mi actitud hacia la gente que hablan inglés es:

$$
\text { ( ) negativo ( )algo negativo ( ) algo positivo ( ) positivo }
$$

3. Mi interés en inglés es :

$$
\text { ( ) bajo ( ) algo bajo ( ) algo alto ( ) alto }
$$

4. Mi deseo para aprender inglés es:

$$
\text { ( ) bajo ( ) algo bajo ( ) algo alto ( ) alto }
$$

5. Mi actitud hacia el aprendizaje del inglés es:

( ) negativo ( ) algo negativo ( ) algo positivo ( ) positivo

6. Mi motivación para aprender inglés para propósitos practicales (p.ej., el trabajo) es :

$$
\text { ( ) bajo ( ) algo bajo ( ) algo alto ( )alto }
$$

7. Mi motivación para aprender inglés para razones personales (p.ej., los hijos) es:

$$
\text { ( ) bajo ( ) algo bajo ( ) algo alto ( ) alto }
$$

8. Mi actitud hacia asistir una clase de inglés es :

( ) negativo ( ) algo negativo ( ) algo positivo ( ) positivo 
Por favor, responda a las siguientes preguntas.

1.¿Cuáles son sus mayores factores de motivación para el aprendizaje del inglés?

2.¿Cómo los roles dentro de la familia han sido afectados por el idioma inglés?

3. ¿El aprendizaje del idioma inglés de los hijos ha impactado la práctica del español y las costumbres culturales en su familia en los EE.UU.? En caso afirmativo, ¿Cómo?

Gracias por tomarse el tiempo para completar esta encuesta. 
Appendix E: Best Practices and Language Models for Hispanic/Latino Immigrant Parents

Advocates for Children of New York

http://www.advocatesforchildren.org/Our_Children_Our_Schools\%20_FINAL_Report.p df?pt $=1$

MALDEF: Mexican American Legal Defense and Educational Fund

http://www.maldef.org/assets/pdf/mco_maldef\%20report_final.pdf

National Council of La Raza

http://issuu.com/nclr/docs/parent_engagement_cqs? $=1871004 / 5450074$

Denver Public Schools

http://diversity.dpsk12.org/initiatives

Maestro en Casa (MATT)

http://www.mattmaestroencasa.org

Miami-Dade County Public Schools-The Parent Academy

http://theparentacademy.dadeschools.net 


\section{Melissa McIntosh}

P.0. Box 618

Ripley. WV 25271

Cell: 540-449-9324

Email: meli.mcintosh@gmail.com

\section{Education}

Ed.D. Curriculum and Instruction. West Virginia University. December 2013

* Concentration: TESOL

Dissertation Title: Exploring a Prefigurative Culture in the Immigrant Family: A look at the sociolinguistic impact of bilingual children on adult English language learners

M.A., Foreign Languages. West Virginia University. August 2007

* Concentration: TESOL

B.A., International Studies/Foreign Languages. West Virginia University. May 2005

* Concentrations: Europe/Spanish, Minor: Geography

* Magna Cum Laude

* Study Abroad: University of Seville, Spain. Spring 2004

Paderno Del Grappa. Italy. Summer 2003

\section{Teaching Experience}

- Institute of Public Administration, Riyadh, Saudi Arabia, 2009-2010

- West Virginia University, Intensive English Program, 2006-2009

- West Virginia University, Department of Curriculum \& Instruction, 2007 *co-taught C\&I 424: Approaches to Language Teaching

\section{Administrative Experience}

- Special Program Advisor for Aichu Shukutoku University at West Virginia University. Responsible for designing a program of activities, events, and classes for a month-long intensive study of English for Japanese students, Fall 2007/2008

- Special Program Advisor for Pukyoung National University at West Virginia University. Responsible for the program of activities and events for a 6-week program of Korean students, Summer 2007/2008

\section{Recruiting Experience}

- Nagoya, Japan, Fall 2007

- Tokyo, Japan, Fall 2007 


\section{Special Skills}

- Spanish, oral and written proficiency

- French, oral and written basics

- Procter and Grader of Michigan Exam

- Procter and Grader of TOEFL Exam

- Computer skills include MS Word, PowerPoint, Excel, Mac OS, SPSS, research portals, web design

\section{Conferences}

- WVTESOL, Morgantown, WV, 2007

Presenter: Corpus Linguistics in the ESL Classroom

- Foreign Language Conference, Morgantown, WV, 2006

- Colloquium of Literature and Film, Morgantown, WV, 2005

Assistant

\section{Academic}

Memberships

- Phi Beta Kappa, 2005

- Sigma Iota Rho-International Studies Honorary, 2004

- Sigma Delta Pi-Spanish Honorary Society, 2004

- Golden Key International Honour Society, 2003

- NSCS-The National Society of Collegiate Scholars, 2003 